Key Words: Heel Stabilization

Hanford ATCD

Grout Backfill

Retention: Permanent

\title{
Stabilizing Grout Compatibility Study
}

John R. Harbour, Thomas B. Edwards, Troy H. Lorier, and Christine A. Langton Westinghouse Savannah River Company

Savannah River Technology Center

Aiken, SC 29808

And

Robert C. Moore, James L. Krumhansl, Kathleen C. Holt, Fred Salas, and Charles A. Sanchez

Sandia National Laboratory

Albuquerque, NM

January 12, 2004

Westinghouse Savannah River Company

Savannah River Site

Aiken, SC 29808

Prepared for the U.S. Department of Energy Under

Contract Number DE-AC09-96SR18500

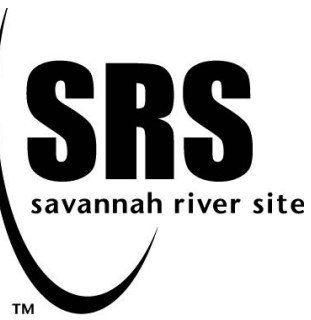


This document was prepared in conjunction with work accomplished under Contract No. DE-AC09-96SR18500 with the U. S. Department of Energy.

\section{DISCLAIMER}

This report was prepared as an account of work sponsored by an agency of the United States Government. Neither the United States Government nor any agency thereof, nor any of their employees, makes any warranty, express or implied, or assumes any legal liability or responsibility for the accuracy, completeness, or usefulness of any information, apparatus, product or process disclosed, or represents that its use would not infringe privately owned rights. Reference herein to any specific commercial product, process or service by trade name, trademark, manufacturer, or otherwise does not necessarily constitute or imply its endorsement, recommendation, or favoring by the United States Government or any agency thereof. The views and opinions of authors expressed herein do not necessarily state or reflect those of the United States Government or any agency thereof.

This report has been reproduced directly from the best available copy.

Available for sale to the public, in paper, from: U.S. Department of Commerce, National Technical Information Service, 5285 Port Royal Road, Springfield, VA 22161, phone: (800) 553-6847, fax: (703) 605-6900

email: orders@ntis.fedworld.gov

online ordering: http://www.ntis.gov/help/index.asp

Available electronically at http://www.osti.gov/bridge

Available for a processing fee to U.S. Department of Energy and its contractors, in paper, from: U.S. Department of Energy, Office of Scientific and Technical Information, P.O. Box 62, Oak Ridge, TN 37831-0062,

phone: (865)576-8401,

fax: (865)576-5728

email: $\underline{\text { reports@ adonis.osti.gov }}$ 
This page was intentionally left blank 


\section{TABLE OF CONTENTS}

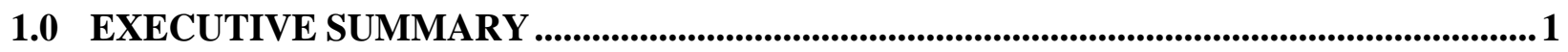

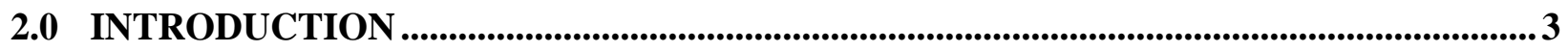

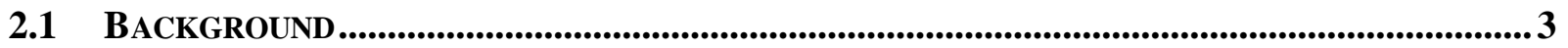

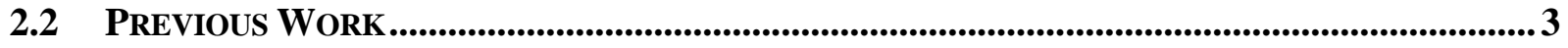

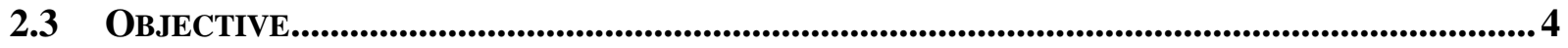

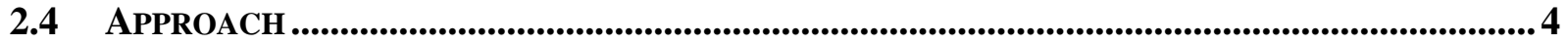

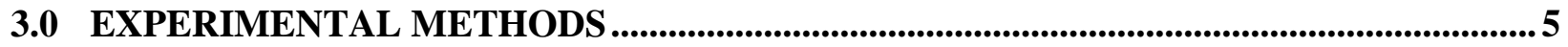

3.1 Non-Radioactive Sample Preparation (Savannah River Technology Center) ...5

3.2 RADIOACTIVE SAMPLE PREPARATION (SNL AND SRTC) ........................................................8

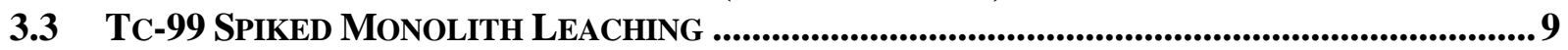

3.4 TC-99 LEACHING FROM CRUSHED SAMPLES....................................................................... 10

3.5 TC-99 SORPTION/DESORPTION ON NON-RADIOACTIVE BINDERS........................................ 11

4.0 RESULTS .............................................................................................................................................. 12

4.1 ANSI/ANS-16.1 MONOLITH LEACHING..................................................................................... 12

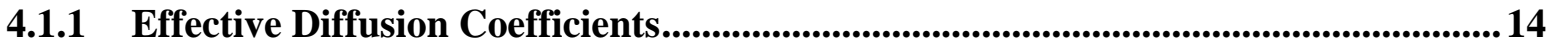

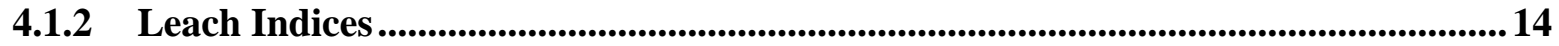

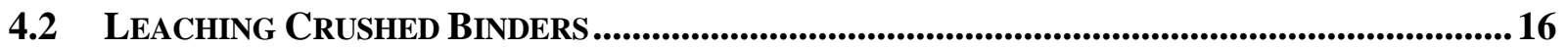

4.3 CRUSHED VERSUS MONOLITHIC RESULTS ............................................................................ 16

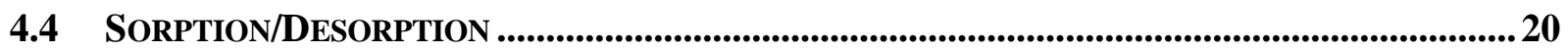

4.4.1 Compatibility of Slag and Hydroxyapatite ......................................................................... 20

4.4.2 Effect of Processing Admixtures on Stabilization ........................................................224

4.4.3 Effect of Sodium Thiosulfate on Hydroxyapatite...........................................................28

4.4.4 Relative Sorption Capacity of Reducing and Non-Reducing Binders....................... 30

5.0 DISCUSSION

5.1 MONOLITH LEACHING ......................................................................................................................31

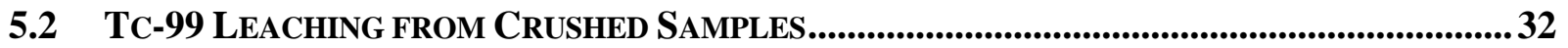

5.3 TC-99 SORPTION/DESORPTION FOR CURED CRUSHED GROUT..............................................33

5.3.1 DI Water Leachate................................................................................................33

5.3.2 DI Water Leaching of Binders with Different Processing Admixtures .................... 34

5.3.3 Effect of Tank Supernate Chemistry on Tc Sorption/desorption............................... 34

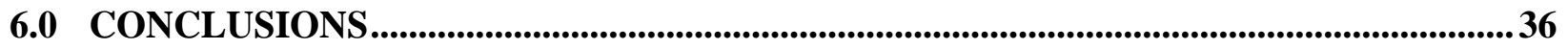

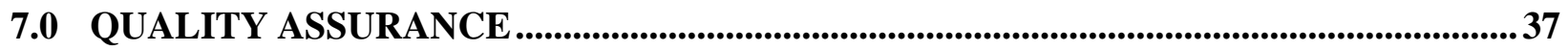

8.0 REFERENCES …....................................................................................................................................... 37 
WSRC-TR-2004-00021, Rev. 0

January 12, 2004

Page iii

\section{List of Tables}

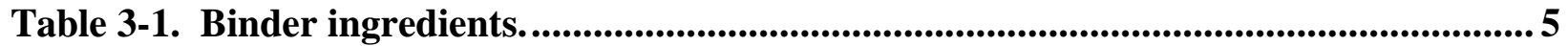

Table 3-2. Binder proportions in Hanford Reducing Grout 2 (HRG 2)................................... 6

Table 3-3. Admixture proportions in HRG 2 and in test binders.............................................6

Table 3-4. Binder mixture ingredients.......................................................................................6 6

Table 3-5. Simulant compositions of $\mathrm{C}-106$ and $\mathrm{C}-200$ tank series........................................... 8

Table 3-6. Binder ingredients for samples used in the monolith leaching tests and Tc-99 desorption tests. ...............................................................................................................................

Table 3-7. Description of Monolithic Samples and Leach Test Parameters.........................9

Table 4-1. Tc-99 leachate concentrations per the ANSI/ANS 16.1 protocol for six binders.

Table 4-2. Uncertainties in the Tc-99 leachate concentrations for each time interval at the two-sigma level.................................................................................................................... 13

Table 4-3. Effective diffusion coefficients for six binder compositions................................... 15

Table 4-4. Leach Indices for six binder compositions. .................................................................. 16

Table 4-5. Tc-99 leachate concentrations for crushed binders as a function of time.......... 17

Table 4-6. Maximum amount of Tc-99 extracted from the crushed samples in any one leach interval in deionized water (expressed as a percentage of the total sorbed on each

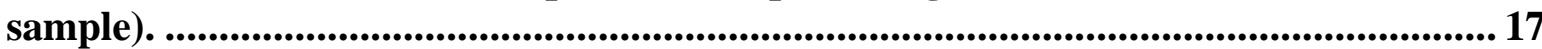

Table 4-7. Tc-99 concentrations in aqueous solutions (DI water, or tank heel supernates) in contact with crushed cured binders. .................................................................................. 21

Table 4-8. Tc-99 concentrations in aqueous solutions (DI water, or tank heel supernates) in contact with crushed cured binders. ........................................................................................ 22

Table 4-9. Tc-99 concentrations in aqueous solutions in contact with crushed cured

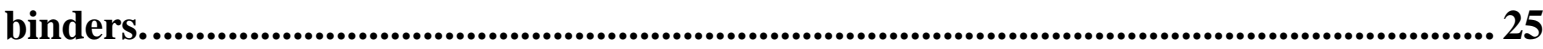

Table 4-10. Cumulative amount of Tc-99 sorbed on 3 grams of crushed binder samples as a function of time and exposure conditions......................................................................... 26

Table 4-11. Tc-99 concentrations in aqueous solutions (DI water, or tank heel supernates) in contact with crushed cured binders containing $\mathrm{HA}$ and sodium thiosulfate............. 28

Table 4-12. Cumulative amount of Tc-99 sorbed on 3 grams of crushed binder samples containing HA and sodium thiosulfate as a function of time and exposure conditions.29

Table 4-13. Percent Tc-99 sorbed on the 3 grams samples after 1, 3, and 5 days exposure.

Table 5-1. Range of effective diffusion coefficients and Leach Indices for all samples tested. 
WSRC-TR-2004-00021, Rev. 0

January 12, 2004

Page iv

\section{LIST OF FIGURES}

Figure 3-1. Ingredients in Hanford Reducing Grout (HRG 2)............................................. 7

Figure 3-2. Examples of binder slurries with slag (left) and without slag (right). .................. 7

Figure 3-3. Photographs of cured $80 \mathrm{~mL}$ binder samples. ....................................................... 7

Figure 3-4. Binders 12 and 13 monoliths in Teflon leaching vessels....................................... 10

Figure 3-5. Sample configuration for the Tc extraction experiments...................................... 10

Figure 3-6. 3 grams of crushed sample in $30 \mathrm{~mL}$ of leachate................................................. 11

Figure 4-1. Plots of time dependence of leaching for monoliths and crushed samples. ...... 18

Figure 4-2. Plots of time dependence of leaching for monoliths and crushed samples. ...... 19

Figure 4-3. Tc-99 retained on 3 grams of samples w/wo slag and HA exposed to DI water.

Figure 4-4. Tc-99 retained on 3 grams of sample w/wo slag and HA in Tank C-106

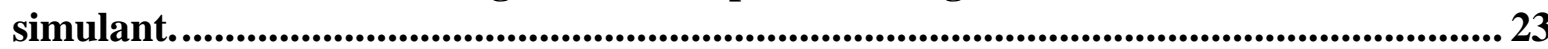

Figure 4-5. Tc-99 retained on 3 grams of sample w/wo slag and HA in Tank C-200 series simulant

Figure 4-6. Tc-99 retained on 3 grams of samples of HRG 2 with 3 different processing admixtures exposed to DI water.

Figure 4-7. Tc-99 retained on 3 gram samples of HRG 2 with 3 different processing admixtures exposed to $\mathrm{C}-106$ simulant.

Figure 4-8. Tc-99 retained on 3-gram samples of HRG 2 with 3 different processing admixtures exposed to $\mathrm{C}-200$ series simulant.

Figure 4-9. Tc-99 retained on 3-gram samples of grout containing $\mathrm{HA}$ and sodium thiosulfate after exposure to 3 different leachates. 
WSRC-TR-2004-00021, Rev. 0

January 12, 2004

Page v

\section{LIST OF ACRONYMS}

$\begin{array}{ll}\text { ANSI/ANS } & \text { American National Standards Institute/American Nuclear Society } \\ \text { ASTM } & \text { American Society for Testing and Materials } \\ \text { ATCD } & \text { Accelerated Tank Closure Demonstration } \\ \text { BBI } & \text { Best-basis inventory } \\ \text { CH2M HILL } & \text { CH2M HILL Hanford Group } \\ \text { Cyd } & \text { Cubic yard } \\ \text { DI } & \text { Deionized (water) } \\ \text { DIW } & \text { Deionized water } \\ \text { DOE } & \text { U. S. Department of Energy } \\ \text { GGBFS } & \text { Ground Granulated Blast Furnace Slag } \\ \text { HA } & \text { Hydroxyapatite (surface treated) } \\ \text { HRG 2 } & \text { Hanford Reducing Grout 2 } \\ \text { LI } & \text { Leachability Index } \\ \text { NB } & \text { Note Book (Laboratory) } \\ \text { PA } & \text { Performance Assessment } \\ \text { RCRA } & \text { Resource Conservation and Recovery Act } \\ \text { SNL } & \text { Sandia National Laboratory } \\ \text { SRTC } & \text { Savannah River Technology Center } \\ \text { TCLP } & \text { Toxicity Characteristic Leaching Procedure } \\ \text { WAC } & \text { Waste Acceptance Criteria } \\ \text { WSRC } & \text { Westinghouse Savannah River Company, LLC }\end{array}$




\subsection{EXECUTIVE SUMMARY}

CH2M HILL has responsibility for High Level Waste Tank Closure at Hanford. This includes waste retrieval, tank cleaning, and filling the empty tanks with portland cement-based materials. The first set of tanks identified for closure includes: C-106, C-201, C-202, C-203, C-204, S-102 and S-112.

$\mathrm{CH} 2 \mathrm{M}$ HILL identified three distinct functions for the tank fill. Three grouts were designated to correspond to each of the three different functions:

- Stabilizing Grout (Phase 1 Grout) to eliminate residual liquid in the tanks and stabilize contaminants (Tc-99) in the residual tank heels,

- Structural Grout (Phase 2 Grout) to provide structural support for the landfill (filling the tank void space), and

- Capping Grout (Phase 3 Grout) to provide an intruder barrier at the top of the tanks.

This report provides data that will be used to formulate the stabilizing grout and includes experimental results for Tc-99 stabilization by two reagents, 1) ground granulated blast furnace slag (GGBFS) and 2) surface treated hydroxyapatite (HA). One or both of these reagents are being considered by $\mathrm{CH} 2 \mathrm{M}$ HILL for incorporation in the binder portion (matrix portion without sand) of the stabilizing grout. The technical basis for identifying the grout ingredient(s) for stabilizing technetium (Tc-99) will be provided by researchers at the Savannah River Technology Center (SRTC) in a subsequent report.

The driver for this particular effort was the need for further exploration of earlier findings at SNL on the limited Tc-99 stabilization by HA in mixtures containing grout-processing admixtures. The work was performed as a joint effort between SRTC and SNL. Simulated non-radioactive binders were prepared and cured at SRTC. Binders containing Tc-99 were prepared and cured at SNL. Leach testing and leachate analyses were performed at SNL. Researchers from both SRTC and SNL performed all of these activities.

In this study, the compatibility of the GGBFS and HA with each other and with the other components in the binders (portland cement, fly ash, and processing admixtures) was evaluated. The effects of three different processing admixture systems, Kelco-Crete ${ }^{\circledR} /$ ADVA $^{\mathrm{TM}}$ Flow, Maxflow $^{\mathrm{TM}} /$ Daracem $^{\mathrm{TM}} 19$, and Methocel $^{\mathrm{TM}}$, were determined.

In addition, the compatibility between the binder portion of the stabilizing grout and simulated Tank C-106 and the C-200 series heel supernates was evaluated. The chemistries of the tank heels were based on information provided by $\mathrm{CH} 2 \mathrm{M}$ HILL and include the expected consequences of the planned waste retrieval activities.

The experimental results demonstrate that:

- Hydroxyapatite is compatible with slag and the Kelco-Crete ${ }^{\circledR} / \mathrm{ADVA}^{\mathrm{Tm}} \mathrm{Flow}$ admixture with respect to Tc-99 stabilization. The data are inconclusive for compatibility of apatite with the other two admixtures, Methocel ${ }^{\mathrm{TM}}$ and MaxFlow ${ }^{\mathrm{Tm}}$.

- $\quad$ Binders containing the Kelco-Crete ${ }^{\circledR} / \mathrm{ADVA}^{\mathrm{TM}}$ Flow admixture system showed the lowest leaching for the crushed samples with DI water in the sorption/desorption tests. Therefore, 
WSRC-TR-2004-00021, Rev. 0

January 12, 2004

Page 2 of 38

the Kelco-Crete ${ }^{\circledR} /$ ADVA $^{\mathrm{TM}}$ Flow system is recommended as the processing admixture for the Hanford tank grouts.

- Binders containing surface treated hydroxyapatite and slag showed no improvement in Tc-99 stabilization compared to slag-only binders for the ANSI/ANS 16.1 leaching tests.

- Tc-99 was stabilized in both the slag- and slag plus HA-modified cement-based binders. Essentially all of the Tc-99 added to fresh binder slurries during mixing was stabilized during the curing process. In other words, $100 \%$ of the Tc-99 spike was precipitated, encapsulated, and/or sorbed and retained by the cured samples over the 27-day leach period for all of the monolithic slag binders and slag plus HA binders tested. (Binders with HA and no slag were not tested in this study.)

- Calculations of the Leach Indices for each binder sample (ANSI/ANS 16.1) using measured values of the Tc-99 concentrations resulted in Leach Indices ranging from 10.5 to 11.4. The range of Leach Indices using plus/minus 2 sigma values for the Tc-99 concentrations gave an overall range of values from 9.2 to 14.2 (95\% confidence interval).

- Calculation of the effective diffusivities using measured Tc-99 values resulted in $\mathrm{D}_{\text {eff }}$ of $1.9 \mathrm{E}-$ 09 to $2.1 \mathrm{E}-10 \mathrm{~cm}^{2} / \mathrm{sec}$. The range using plus/minus 2 sigma values for the Tc-99 concentrations gave an overall range from $1.3 \mathrm{E}-09$ to $1.1 \mathrm{E}-14 \mathrm{~cm}^{2} / \mathrm{sec}(95 \%$ confidence interval). These data can be used in support of Performance Assessment calculations performed for HLW tank closure at Hanford.

- Binders containing surface treated hydroxyapatite and slag showed improvement in Tc-99 stabilization compared to slag-only binders for the crushed leaching tests when Tc-99 sorption occurred from the Tank C-106 simulant. This presence of hydroxyapatite reduced leaching in this case by a factor of 4 . Results from the crushed samples using either DI water or C-200 simulant were inconclusive in this regard.

- Cured crushed binders containing slag or slag plus HA were shown to stabilize/sorb Tc-99 from DI water, C-106 supernate, and average C-200 series tank supernate. (This set of data was intended to simulate the case where rainwater infiltrates into the tank, dissolves Tc-99 from the walls of the tank, and then contacts the cured stabilization grout. DI water and the tank supernates were used to bound the composition of the infiltrating aqueous phase.)

- $\quad$ Cured grout containing slag will sorb Tc-99.

- Surface treated apatite in binders (with or without slag) did not sorb nor influence the stabilization of the Tc-99.

- $\quad$ Desorption of Tc-99 from binders containing Kelco-Crete ${ }^{\circledR} /$ ADVA $^{\mathrm{TM}}$ Flow was considerably less than for binders with either Methocel or MaxFlow for DI water.

- 10 to $20 \%$ desorption of Tc-99 was observed for the tank simulant cases while $40 \%$ desorption of Tc-99 occurred in the DI water test.

- All three processing admixtures resulted in self-leveling, zero bleed water binders.

The results can be applied to the following scenarios: 1) leaching from a layer of stabilizing grout, 2) stabilization of soluble Tc-99 (leached from the tank walls) by contact with cured grout containing slag, and 3) stabilization of Tc in tank supernate in contact with cured or uncured grout. 


\subsection{INTRODUCTION}

\subsection{Background}

Single-shell tanks (SST) high-level waste (HLW) will be closed, i.e., permanently removed from service, as part of the Hanford Site closure program. Tank closure includes; waste retrieval, heel stabilization, and subsidence abatement. Empty tanks will be physically stabilized with dimensionally stable materials and residual radionuclides of concern will be chemically stabilized with selected reagents to reduce migration and transport into the environment. Five single-shell tanks in the 241-C Tank Farm: Tank 241-C-201, Tanks 241-C-201 to C-204 plus two additional tanks, S-102 and S-112 will be the first to be closed [1].

In 2002, CH2M HILL initiated a multi-laboratory test program (Sandia National Laboratory and Savannah River Technology Center) to provide the technical basis for specifying the tank fill materials. Technology required to support this effort includes:

- Establishing material and performance requirements.

- Characterizing the tank heel and site specific requirements.

- Designing and demonstrating materials for heel stabilization, structural fill, and capping.

- Providing guidance for delivering and placing these materials in the tanks.

The information generated in this effort will also be applicable to other tanks at Hanford that have similar heel chemistries and closure requirements.

\subsection{Previous Work}

The technology development effort for closing the Hanford HLW tanks was based on previous tank closure experience at SRS. This study combines zero-bleed self-leveling grouts developed at SRS/SRTC (implemented during the closure of two high-level waste tanks at SRS) and promising test results from SNL on technetium stabilization. Researchers at SNL reported that cow bone calcined at about $600^{\circ} \mathrm{C}$ to form hydroxyapatite, $\mathrm{Ca}_{10}\left(\mathrm{PO}_{4}\right)_{6}(\mathrm{OH})_{2}$, and surface treated with a chemical reductant, stannous chloride, is effective in irreversibly sorbing Tc-99 from aqueous solutions [2].

Testing at SNL also indicated that stannous chloride surface treated hydroxyapatite (HA) irreversibly sorbed Tc-99 from simulated Hanford waste solutions [3]. Subsequent scoping tests at SNL suggested that the HA was not effective in sorbing Tc-99 in the presence of portland cement and mixtures of Kelco-Crete ${ }^{\circledR} /$ ADVA $^{\mathrm{T}}$ Flow, which is used to enhance grout processibility. In these initial HA-grout compatibility tests, leaching was performed at $90^{\circ} \mathrm{C}$ using a test designed to rank radioactive waste glass with respect to durability. Very high doses of processing admixtures were also used [4].

The need to repeat the initial testing using more realistic dosages of processing admixtures and binder proportions was realized, and screening tests were performed at SNL. Results from the second set of screening tests were more encouraging and indicated under the revised test conditions, surface treated HA and grout binder ingredients are compatible with and may even be complimentary with respect to Tc-99 sorption/stabilization [5].

Based on encouraging results, a joint effort between SRTC and SNL was initiated to provide a rapid determination of the potential for Tc-99 stabilization in portland cement-based grout 
WSRC-TR-2004-00021, Rev. 0

January 12, 2004

Page 4 of 38

prepared with and without stannous chloride treated hydroxyapatite. The test materials were limited to the binder fraction of the stabilization grout. In other words, sand, which is considered inert, was not included in the test samples.

In addition, since this was the only testing identified to quantify Tc-99 leaching from the Hanford stabilizing grout, the sorption/leaching experiments were designed to serve the dual purpose of supplying data for use in the Hanford Tank Closure performance assessment. Several leaching scenarios were constructed to simulate tank conditions that may be encountered as a function of time after closure.

\subsection{Objective}

The objective of this task was to evaluate the effectiveness of stannous chloride-treated hydroxyapatite in stabilizing/sorbing $\mathrm{Tc}^{+7}$ when incorporated in stabilizing grout formulated for closing Hanford waste tanks. Specific objectives include:

- Determine whether grout ingredients (portland cement, blast furnace slag, and fly ash), processing additives (Kelco-Crete ${ }^{\circledR} / \mathrm{ADVA}^{\mathrm{TM}}$ Flow, Maxflow ${ }^{\mathrm{TM}}$, and Methocel $^{\mathrm{TM}}$ ), and additional stabilizing reagents (sodium thiosulfate) interfered with the sorption of $\mathrm{Tc}^{+7}$ by the treated hydroxyapatite.

- Evaluate heel-grout mixing/contact scenarios and leaching scenarios.

The data generated from the joint effort between SNL and SRTC will be used to specify materials for stabilizing the heels in Tanks C-106, C-201 to 204, S-102 and S-112 and other tanks at Hanford that have similar heel chemistries. Leaching data for the stabilizing grouts will also be generated to support the Hanford Tank Performance Assessment (PA) modeling effort.

CH2M HILL requested and funded this task through the Savannah River Technology Center (Requisition No. MOSRLE81) [6] and SNL [7].

\subsection{Approach}

The approach was to incorporate surface-treated hydroxyapatite in binders (mixtures of portland cement, blast furnace slag, and fly ash) with three different admixture systems (surfactants, thickeners, and/or set retarders) and to identify factors that impact Tc sorption/desorption. Since this study focused on the chemical interactions between the grout and hydroxyapatite, sand (considered to be inert) was not included in the test samples.

The ANSI/ANS 16.1 test was used to measure Tc-99 leaching from monolithic, well-mixed heelgrout waste forms. An extraction test was used to measure Tc-99 leaching from crushed samples. Sorption of Tc-99 onto crushed binder and subsequent desorption were also measured. Tc-99 spiked DIW, Tank C-106 heel simulant and average C-200 series tank simulant were used as the contact liquids in the sorption/desorption tests. These tests were intended to provide an indication of the ability of the cured grout to retard Tc-99 from leaching off of the tank walls.

The work was performed as a joint program between SRTC and SNL. SNL provided the surfacetreated hydroxyapatite. SRTC personnel identified the binders and admixtures to be tested and prepared non-radioactive samples for sorption-desorption tests. SNL and SRTC personnel prepared radioactive samples spiked with Tc-99 at SNL. Sorption-desorption tests and ANSI/ANS 16.1 leaching tests were performed at SNL. 


\subsection{EXPERIMENTAL METHODS}

\subsection{Non-Radioactive Sample Preparation (Savannah River Technology Center)}

Eleven binder formulations were proposed for evaluating the performance of hydroxyapatite in cementitious grouts containing various processing admixtures (see Table 3-1). The binder batch size was $1000 \mathrm{~g}$ of dry solids which was compatible with a $2.5 \mathrm{~L}$ Hobart mixer. The proportions of the cementitious ingredients in the binders (cement, slag, and fly ash) were the same as those in Hanford Reducing Grout Mix, HRG 2. See Table 3-2.

The dry binder ingredients were premixed in a plastic bag. They were added to water containing the selected admixture and mixed for two minutes in a Hobart mixer. The bowl was then scraped and the slurry was mixed for another two minutes. Hydroxyapatite was added to some of the slurries and mixing was resumed at low speed for another two minutes. The binders were poured into plastic molds, capped, placed in sealed plastic bags and cured for at least 28 days prior to evaluating Tc-99 sorption and leaching. During curing, samples were shipped to SNL for testing.

The processing admixtures were approximately scaled to the proportions used in actual stabilizing grout mixes (See Table 3-3). Extra water was added to some of the binders to achieve pourable, self-leveling slurries. The hydroxyapatite was crushed to approximately -60 to +200 mesh and was coarser than any of the cementitious binder ingredients as illustrated in Figure 3-1.

Only seven binders were selected for preparation and leach testing due to SNL funding constraints. The ingredients and proportions of the seven mixes are listed in Table 3-4. Two additional mixes, Binders 5A and 5B, were prepared at the request of SNL personnel to evaluate the effect of apatite loading on Tc sorption/stabilization. Extra hydroxyapatite was added to Binder 5 as shown in Table 3-4. (These mixes were not included in this study.)

Table 3-1. Binder ingredients.

\begin{tabular}{|c|c|c|c|c|c|c|c|c|c|c|c|}
\hline \multirow{2}{*}{ Ingredients } & \multicolumn{11}{|c|}{ Binder Number } \\
\hline & 1 & 2 & 3 & 4 & 5 & 6 & 7 & 8 & 9 & 10 & 11 \\
\hline Water & $\mathrm{X}$ & $\mathrm{X}$ & $\mathrm{X}$ & $\mathrm{X}$ & $\mathrm{X}$ & $\mathrm{X}$ & $\mathrm{X}$ & $\mathrm{X}$ & $\mathrm{X}$ & $\mathrm{X}$ & $\mathrm{X}$ \\
\hline Cement & $\mathrm{X}$ & $\mathrm{X}$ & $\mathrm{X}$ & $\mathrm{X}$ & $\mathrm{X}$ & $X$ & $\mathrm{X}$ & $\mathrm{X}$ & $\mathrm{X}$ & $\mathrm{X}$ & $\mathrm{X}$ \\
\hline Slag & $\mathrm{X}$ & $\mathrm{X}$ & $\mathrm{X}$ & $\mathrm{X}$ & $\mathrm{X}$ & $\mathrm{X}$ & - & - & - & - & - \\
\hline Fly Ash & $\mathrm{X}$ & $\mathrm{X}$ & $\mathrm{X}$ & $\mathrm{X}$ & $\mathrm{X}$ & $\mathrm{X}$ & $X$ & $\mathrm{X}$ & $X$ & $\mathrm{X}$ & $\mathrm{X}$ \\
\hline H Apatite w/Sn & - & - & - & $\mathrm{X}$ & $\mathrm{X}$ & $\mathrm{X}$ & $\mathrm{X}$ & $\mathrm{X}$ & $\mathrm{X}$ & $\mathrm{X}$ & - \\
\hline $\begin{array}{l}\text { Kelco-Crete }^{\circledR} / \\
\text { ADVA }^{\mathrm{T}} \text { Flow }\end{array}$ & $\mathrm{X}$ & - & - & $\mathrm{X}$ & - & - & $\mathrm{X}$ & - & $\mathrm{X}$ & $\mathrm{X}$ & $\mathrm{X}$ \\
\hline Methocel $^{\text {IM }}$ & - & $\mathrm{X}$ & - & - & $\mathrm{X}$ & - & - & $\mathrm{X}$ & - & - & - \\
\hline MaxFlow $^{\text {TM }}$ & - & - & $\mathrm{X}$ & - & - & $\mathrm{X}$ & - & - & $\mathrm{X}$ & - & - \\
\hline Na thiosulfate & - & - & - & - & - & - & - & - & - & $X$ & - \\
\hline Mix Objective & \multicolumn{3}{|c|}{$\begin{array}{c}\text { Vary Admixture, } \\
\text { w/o HA }\end{array}$} & \multicolumn{3}{|c|}{$\begin{array}{c}\text { Vary Admixture, } \\
\text { w/ HA }\end{array}$} & \multicolumn{3}{|c|}{$\begin{array}{l}\text { Vary Admixture, } \\
\text { w/ HA, No Slag }\end{array}$} & $\begin{array}{l}\mathrm{Na}_{2} \mathrm{~S}_{2} \mathrm{O}_{3} \\
\text { No Slag }\end{array}$ & Control \\
\hline
\end{tabular}

* Mixes in the shaded columns were removed from the test matrix to reduce the size of the leaching matrix due to funding constraints. 
WSRC-TR-2004-00021, Rev. 0 January 12, 2004

Page 6 of 38

Table 3-2. Binder proportions in Hanford Reducing Grout 2 (HRG 2).

\begin{tabular}{|l|c|c|c|}
\hline \multirow{2}{*}{ Binder Ingredient } & \multicolumn{2}{|c|}{ HRG 2 } & \\
\cline { 2 - 4 } Cement & lbs./cyd & Wt. \% & g/1000 gram batch \\
\hline Slag & 75 & 11 & 110 \\
\hline Fly ash & 210 & 32 & 320 \\
\hline Total & 375 & 57 & 570 \\
\hline
\end{tabular}

Table 3-3. Admixture proportions in HRG 2 and in test binders.

\begin{tabular}{|c|l|c|c|c|}
\hline & & \multicolumn{3}{|c|}{ HRG 2 } \\
\hline Admixture No. & \multicolumn{1}{|c|}{ Admixture } & Amount/cyd & Comments & g/1000 gram batch \\
\hline $\mathbf{1}$ & $\begin{array}{l}\text { Kelco-Crete }^{\circledR} / \\
\text { ADVA }^{\mathrm{m}} \mathrm{Flow}\end{array}$ & $\begin{array}{c}90 \mathrm{fl.oz.}+ \\
275 \mathrm{~g}\end{array}$ & $\begin{array}{c}\text { Pre-mix ratio } \\
10 \mathrm{~mL}+1 \mathrm{~g}\end{array}$ & $\begin{array}{c}(0.2 \mathrm{~g} \text { Kelco-Crete }) \\
2 \mathrm{~mL} \text { of } 10 \mathrm{~mL}: 1 \mathrm{~g} \\
\text { mixture }\end{array}$ \\
\hline $\mathbf{2}$ & Methocel $^{\mathrm{m}}$ & $380 \mathrm{~g}$ & - & $0.28 \mathrm{~g}$ \\
\hline $\mathbf{3}$ & MaxFlow $^{\mathrm{mm}}$ & $30 \mathrm{lbs}$ foam & $\begin{array}{c}\text { Prepare foam } \\
\text { in blender }\end{array}$ & $\begin{array}{c}\text { Add } 10 \mathrm{~g} \text { of pre-formed } \\
\text { foam }\end{array}$ \\
\hline $\mathbf{4}$ & Na thiosulfate & $3 \mathrm{lbs}$. & - & 0.1 to $0.05 \mathrm{~g}$ \\
\hline
\end{tabular}

Table 3-4. Binder mixture ingredients. (in grams unless otherwise indicated)

\begin{tabular}{|c|c|c|c|c|c|c|c|c|c|}
\hline Ingredient & 1 & 4 & 5 & 6 & 7 & 10 & 11 & $5 \mathrm{~A}$ & 5B \\
\hline Water & 292 & 302 & 354 & 315 & 325 & 325 & 325 & g Binder & g Binder \\
\hline Cement & 110 & 110 & 110 & 110 & 270 & 270 & 270 & $\begin{array}{l}\text { A }+ \\
+10 \mathrm{~g} \text { extra }\end{array}$ & $\begin{array}{l}A J+ \\
13 \mathrm{~g} \text { ex }\end{array}$ \\
\hline Slag & 320 & 320 & 320 & 320 & - & $\begin{array}{ll}- \\
-\end{array}$ & - & $\begin{array}{l}\text { water + extra } \\
\text { hydroxy- }\end{array}$ & $\begin{array}{l}\text { water }+ \text { ex } \\
\text { hydroxy- }\end{array}$ \\
\hline Fly Ash & 570 & 570 & 570 & 570 & 730 & 730 & 730 & apatite & apatite \\
\hline $\begin{array}{l}\text { Hydr } \\
\text { w/Sn }\end{array}$ & - & 75 & 75 & 75 & 75 & 75 & - & $10 \mathrm{~g}$ & $25 \mathrm{~g}$ \\
\hline $\begin{array}{l}\text { Kelco- } \\
\text { ADVA }\end{array}$ & $2 \mathrm{~mL}$ & $2 \mathrm{~mL}$ & - & - & $2 \mathrm{~mL}$ & $2 \mathrm{~mL}$ & $2 \mathrm{~mL}$ & 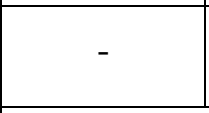 & - \\
\hline Methocel $^{\text {TM }}$ & - & - & $0.28 \mathrm{~g}$ & - & $\begin{array}{l}- \\
-\end{array}$ & - & - & \multirow{3}{*}{\multicolumn{2}{|c|}{$\begin{array}{l}\text { After mixing Binder } 5 \text {, } \\
\text { extra hydroxyapatite } \\
\text { was added to } \# 5 \text { to } \\
\text { evaluate the effect of } \\
\text { hydroxyapatite loading. }\end{array}$}} \\
\hline MaxFlow $^{m}$ & - & - & - & $\begin{array}{l}20 \mathrm{~g} \\
\text { foam } \\
\end{array}$ & - & - & - & & \\
\hline Na thiosulfate & - & - & - & - & . & 0.102 & - & & \\
\hline
\end{tabular}


WSRC-TR-2004-00021, Rev. 0

January 12, 2004

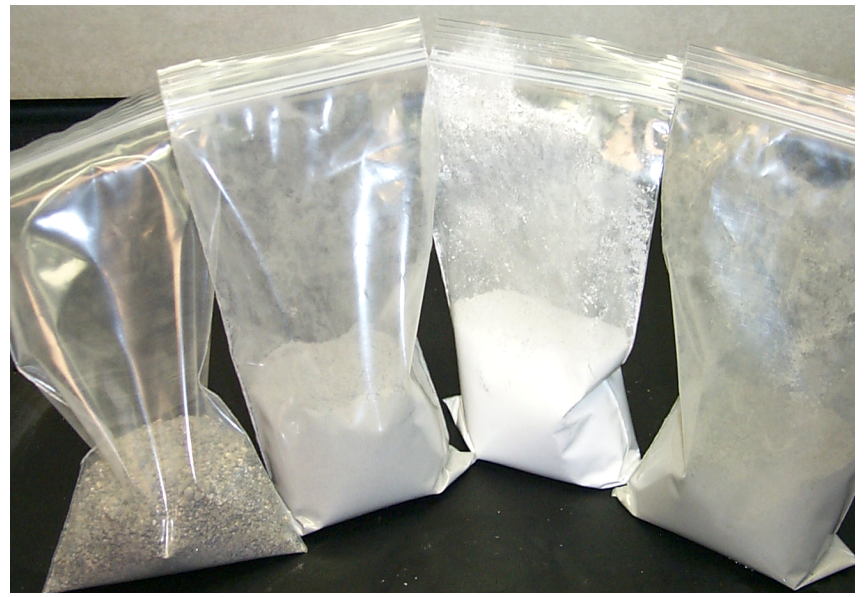

Page 7 of 38

Figure 3-1. Ingredients in Hanford Reducing Grout (HRG 2).

Proceeding from left to right in Figure 3-1, the ingredients are Hanford ASTM C-33 sand (supplied by Central PreMix Concrete Company), ISG Resources Class F fly ash, Holcim slag, Ash Grove portland cement, and stannous chloride-treated hydroxyapatite (supplied by R. C. Moore, SNL). As previously stated, sand was not included in the mixes used in this study.
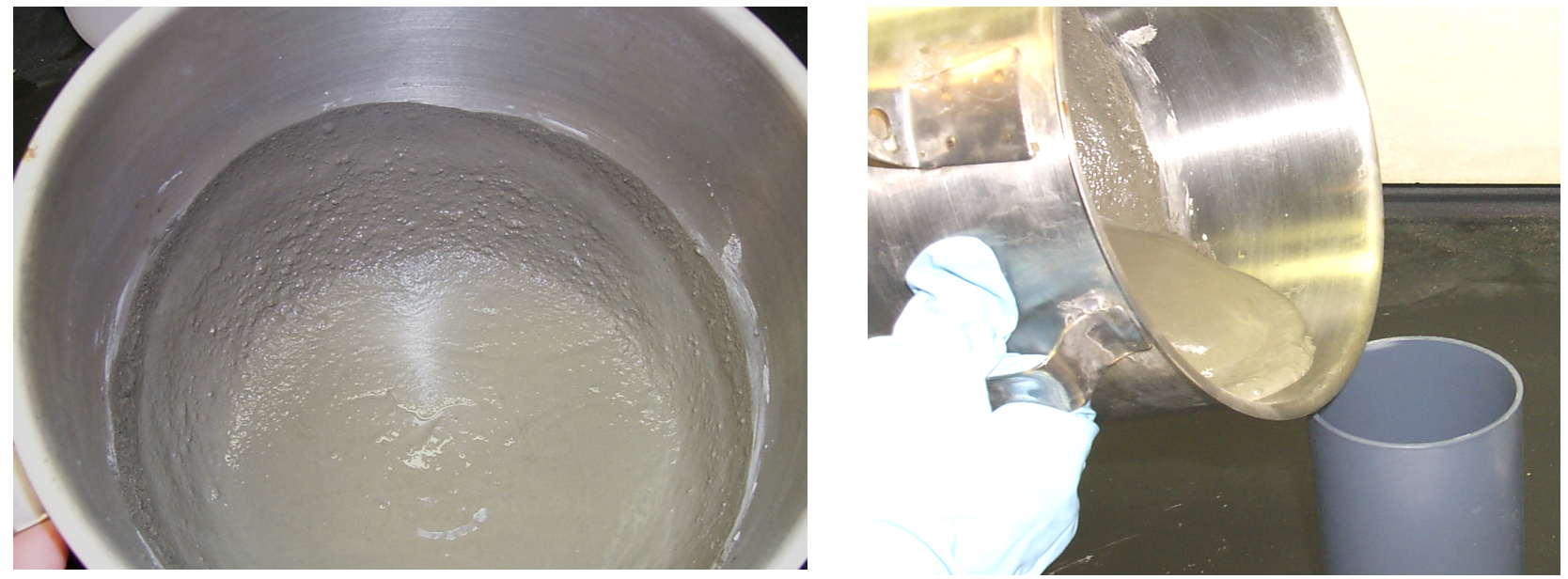

Figure 3-2. Examples of binder slurries with slag (left) and without slag (right).

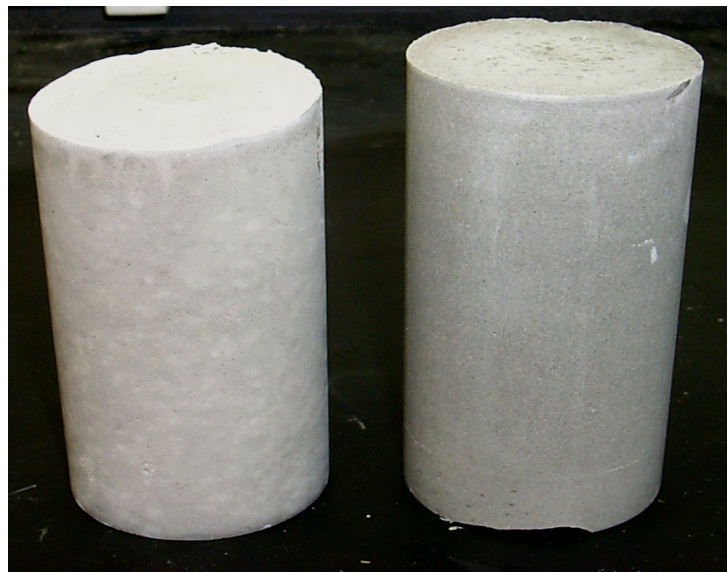

The $80 \mathrm{~mL}$ samples were crushed and used for the sorption/desorption testing. The $30 \mathrm{~mL}$ samples were used as monoliths in the ANSI/ANS 16.1 tests performed at SNL.

Figure 3-3. Photographs of cured $80 \mathrm{~mL}$ binder samples. 


\subsection{Radioactive Sample Preparation (SNL and SRTC)}

Six binder samples containing Tc-99 were prepared at SNL. These samples were prepared with Tc-99 spiked deionized water (DIW), Tank C-106 simulant or average C-200 Series tank simulant. The water in the simulants served as the mixing water for the samples. Each simulant was used to prepare two samples: one containing slag as the only Tc-99 stabilization reagent and the other with both slag and hydroxyapatite.

J. Krumhansl, SNL, proposed chemical simulants for the experimental study based on information provided by D. Reynolds and J. Laurenz, CH2M HILL [8 and 9, respectively]. The C-106 and Average C-200 Series simulant compositions were derived from the estimated heel compositions after retrieval. Retrieval for tank C-106 was assumed to include the following activities: heel removal, oxalic acid washing, water washing, and $\mathrm{pH}$ adjustment with sodium hydroxide solution. Retrieval for the other six tanks involves only solid heel removal at the present time [9]. Since a small amount of wash water will be added to one of the C-200 tanks, an average supernate composition was estimated from the soluble salts in these tanks. The Best-Basis Inventories (BBI) were used to define the pre-retrieval starting compositions.

CH2M HILL requested that this leaching study be limited to Tc-99 since it is the only contaminant of concern at the present time. Simulants compositions were approved by J. Laurenz, CH2M HILL on June 19, 2003. See Table 3-5.

Table 3-5. Simulant compositions of C-106 and C-200 tank series.

\begin{tabular}{|c|c|c|c|}
\hline \multicolumn{2}{|c|}{ C-106 Simulant } & \multicolumn{2}{|c|}{ C-200 Simulant } \\
\hline Ingredient & Concentration & Ingredient & Concentration \\
\hline $\mathrm{NaOH}$ & $0.43 \mathrm{M}$ & $\mathrm{KCl}$ & $0.0045 \mathrm{M}$ \\
\hline $\mathrm{Na}_{2} \mathrm{C}_{2} \mathrm{O}_{4}$ & $0.02 \mathrm{M}$ & $\mathrm{NaNO}_{3}$ & $0.172 \mathrm{M}$ \\
\hline DI water & & $\mathrm{NaNO}_{2}$ & $0.068 \mathrm{M}$ \\
\hline \multirow{7}{*}{$\begin{array}{l}\text { Tc-99 stock solution } \\
\mathrm{NH}_{4} \mathrm{TcO}_{4}, 0.5 \mathrm{mCi} / \mathrm{ml}\end{array}$} & \multirow[b]{2}{*}{$10^{-5} \mathrm{M}$} & $\mathrm{NaSO}_{4}$ & $0.017 \mathrm{M}$ \\
\hline & & $\mathrm{Na}_{2} \mathrm{CO}_{3}$ & $0.122 \mathrm{M}$ \\
\hline & & $\mathrm{Na}_{2} \mathrm{C}_{2} \mathrm{O}_{4}$ & $0.024 \mathrm{M}$ \\
\hline & & $\mathrm{NaF}$ & $0.023 \mathrm{M}$ \\
\hline & & $\mathrm{Al}(\mathrm{OH})_{3}$ & $1.54 \mathrm{M}$ \\
\hline & & DI water & \\
\hline & & $\begin{array}{l}\text { Tc-99 stock solution } \\
\mathrm{NH}_{4} \mathrm{TcO}_{4}, 0.5 \mathrm{mCi} / \mathrm{ml}\end{array}$ & $10^{-5} \mathrm{M}$ \\
\hline
\end{tabular}

Each binder was prepared by adding a pre-blended mixture of cement, slag, and fly ash, to the mixing solution, which contained a processing admixture, Kelco-Crete ${ }^{\circledR} / \mathrm{ADVA}^{\mathrm{TM}} \mathrm{Flow}$, and $10 \mu \mathrm{L}$ of the Tc-99 stock solution. The hydroxyapatite crushed to -60 to +200 mesh was the last ingredient added to the binders. 
In some cases additional mixing solution was required after the hydroxyapatite was added to achieve pourable slurries. The apatite used in this study is very porous and consequently causes the mixes to have a higher water demand than non-porous aggregates. The ingredients and proportions for each binder made on June 19, 2003, are provided in Table 3-6. After mixing, the binders were cast into containers that were sealed and cured for 28 days at ambient temperature before starting the leach testing.

Table 3-6. Binder ingredients for samples used in the monolith leaching tests and Tc-99 desorption tests.

\begin{tabular}{|l|c|c|c|c|c|c|}
\hline Ingredient & $\begin{array}{c}\text { Binder } \\
\mathbf{1 2}\end{array}$ & $\begin{array}{c}\text { Binder } \\
\mathbf{1 3}\end{array}$ & $\begin{array}{c}\text { Binder } \\
\mathbf{1 6}\end{array}$ & $\begin{array}{c}\text { Binder } \\
\mathbf{1 4}\end{array}$ & $\begin{array}{c}\text { Binder } \\
\mathbf{1 5}\end{array}$ & $\begin{array}{c}\text { Binder } \\
\mathbf{1 7}\end{array}$ \\
\hline Tc-spiked DIW & $360 \mathrm{~mL}$ & --- & --- & $360 \mathrm{~mL}$ & --- & --- \\
\hline Tc-spiked C-106 & --- & $400 \mathrm{~mL}$ & --- & --- & $440 \mathrm{~mL}$ & --- \\
\hline Tc-spiked C-200 & --- & --- & $500 \mathrm{~mL}$ & --- & --- & $500 \mathrm{~mL}$ \\
\hline Cement & $115 \mathrm{~g}$ & $115 \mathrm{~g}$ & $115 \mathrm{~g}$ & $115 \mathrm{~g}$ & $115 \mathrm{~g}$ & $115 \mathrm{~g}$ \\
\hline Slag & $320 \mathrm{~g}$ & $320 \mathrm{~g}$ & $320 \mathrm{~g}$ & $320 \mathrm{~g}$ & $320 \mathrm{~g}$ & $320 \mathrm{~g}$ \\
\hline Fly ash & $570 \mathrm{~g}$ & $570 \mathrm{~g}$ & $570 \mathrm{~g}$ & $570 \mathrm{~g}$ & $570 \mathrm{~g}$ & $570 \mathrm{~g}$ \\
\hline Kelco-Crete ${ }^{\circledR} /$ ADVA ${ }^{\mathrm{Tm}}$ Flow & $2 \mathrm{~mL}$ & $2 \mathrm{~mL}$ & $2 \mathrm{~mL}$ & $2 \mathrm{~mL}$ & $2 \mathrm{~mL}$ & $2 \mathrm{~mL}$ \\
\hline Hydroxyapatite & $0 \mathrm{~g}$ & $0 \mathrm{~g}$ & $0 \mathrm{~g}$ & $75 \mathrm{~g}$ & $75 \mathrm{~g}$ & $75 \mathrm{~g}$ \\
\hline $\begin{array}{l}\text { Water/Cementitious Solids } \\
\text { Ratio }\end{array}$ & 0.358 & 0.390 & 0.423 & 0.358 & 0.429 & 0.423 \\
\hline
\end{tabular}

\subsection{Tc-99 Spiked Monolith Leaching}

The Tc-99 spiked samples were leached as monoliths according to a modified ANSI/ANS 16.1 accelerated test protocol [10]. After curing 28 days, the $30 \mathrm{~mL}$ cylinders were demolded and measured. The sample surface areas, Tc-99 concentrations, and total Tc-99 loadings were calculated. See Table 3-7. The samples were placed in $500 \mathrm{~mL}$ Teflon leach vessels with DIW (10 cm times the sample surface area) per the ANS 16.1 protocol. The leach intervals were $30 \mathrm{~s}$ and 2, 7, 24, 48, 120, and $624 \mathrm{hrs}$. The test configuration is illustrated in Figure 3-4.

Table 3-7. Description of Monolithic Samples and Leach Test Parameters.

\begin{tabular}{|c|c|c|c|c|c|c|c|}
\hline $\begin{array}{c}\text { Sample } \\
\text { No. }\end{array}$ & $\begin{array}{c}\text { Sample } \\
\text { length } \\
(\mathbf{c m})\end{array}$ & $\begin{array}{c}\text { Sample } \\
\text { diameter } \\
(\mathbf{c m})\end{array}$ & $\begin{array}{c}\text { Sample } \\
\text { surface area } \\
\left(\mathbf{c m}^{\mathbf{2}}\right)\end{array}$ & $\begin{array}{c}\text { Leachate } \\
\text { Volume } \\
\left(\mathbf{c m}^{\mathbf{3}}\right)\end{array}$ & $\begin{array}{c}\text { Initial } \\
\text { Sample } \\
\text { Weight } \mathbf{( g )}\end{array}$ & $\begin{array}{c}\text { Tc-99 } \mathbf{C}_{\mathbf{0}} \\
(\mathbf{p C i} / \mathbf{g})\end{array}$ & $\begin{array}{c}\text { Tc-99 } \\
\text { Total } \\
(\mathbf{p C i})\end{array}$ \\
\hline 12 & 4.2 & 2.0 & 32.7 & 327 & 31.16 & $3.66 \times 10^{3}$ & $1.14 \times 10^{5}$ \\
\hline 13 & 4.3 & 2.0 & 33.3 & 333 & 30.47 & $3.55 \times 10^{3}$ & $1.08 \times 10^{5}$ \\
\hline 14 & 4.3 & 2.0 & 33.3 & 333 & 31.62 & $3.47 \times 10^{3}$ & $1.10 \times 10^{5}$ \\
\hline 15 & 4.2 & 2.0 & 32.7 & 327 & 29.84 & $3.29 \times 10^{3}$ & $9.80 \times 10^{4}$ \\
\hline 16 & 4.0 & 2.0 & 31.4 & 314 & 28.00 & $3.32 \times 10^{3}$ & $9.29 \times 10^{4}$ \\
\hline 17 & 4.0 & 2.0 & 31.4 & 314 & 26.67 & $3.16 \times 10^{3}$ & $8.43 \times 10^{4}$ \\
\hline
\end{tabular}


WSRC-TR-2004-00021, Rev. 0

January 12, 2004

Page 10 of 38
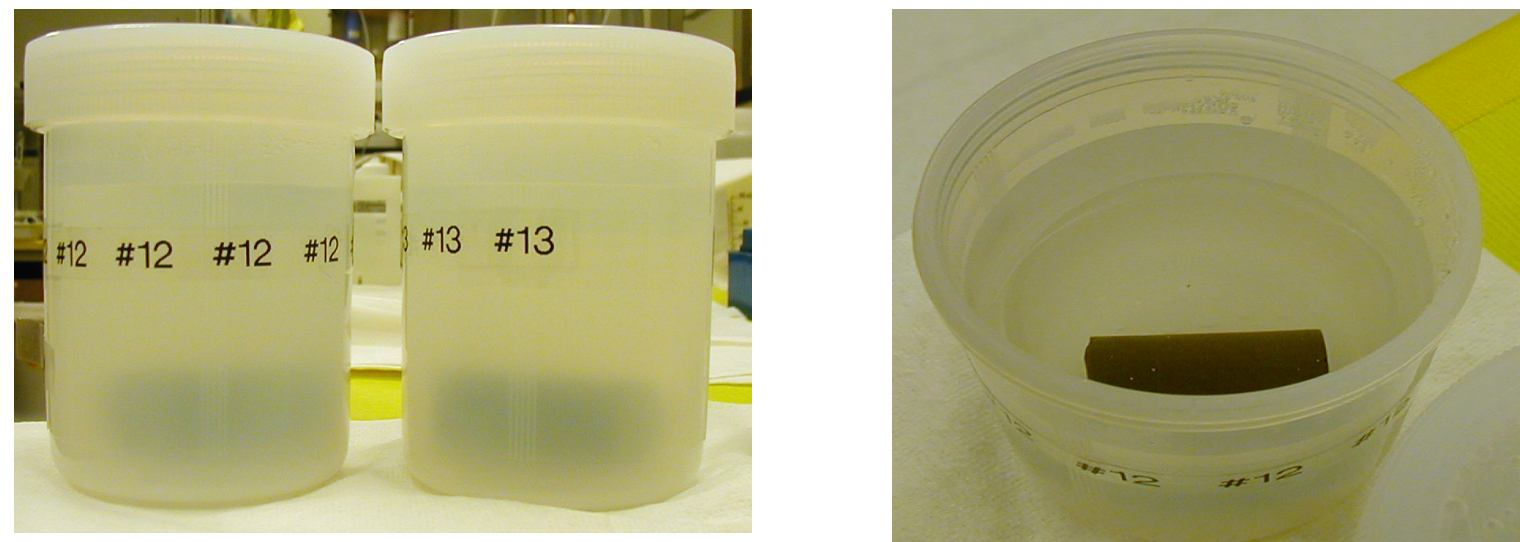

Figure 3-4. Binders 12 and 13 monoliths in Teflon leaching vessels.

\subsection{Tc-99 Leaching from Crushed Samples}

A second set of Tc-99 spiked binder samples was prepared for Tc-99 extraction/leaching tests per a modified ASTM D-5233, Single Batch Extraction Method for Wastes [11]. Binders cured for at least 28 days were crushed with a hammer to approximately $2 \mathrm{~mm}$ sized particles. These samples were not sieved because the work was performed in a radiological hood and crushing to a finer particle size was not practical. Three grams of the crushed material from each binder were placed in a 35-mL centrifuge tube. The extraction fluids (leachates) consisted of $30 \mathrm{~mL}$ of DIW, C-106 simulant, or C-200 simulant. Leachates were sampled after 1, 5 and 27 days. Small amounts of each leachate were removed from the centrifuge tubes with a syringe at each interval and filtered through a $0.045 \mu \mathrm{m}$ nylon filter. Duplicate $1-\mathrm{mL}$ samples of filtered leachate were collected for each leach interval. Figure 3-5 illustrates the sample configuration.

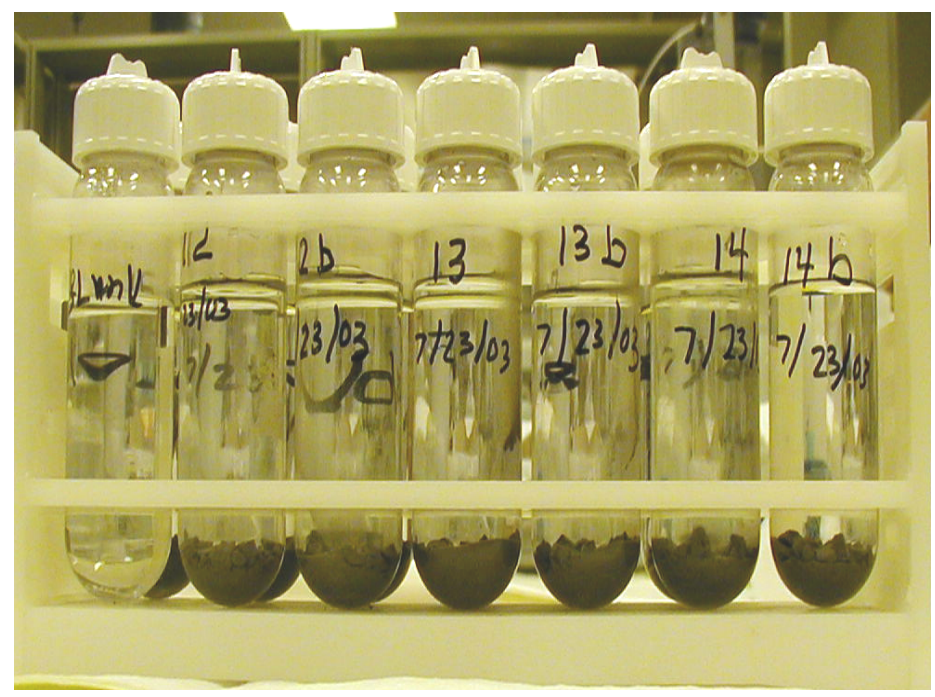

Figure 3-5. Sample configuration for the Tc extraction experiments.

Three grams of crushed sample in $30 \mathrm{~mL}$ of leachate (plus blank on far left). 


\subsection{Tc-99 Sorption/Desorption on Non-Radioactive Binders}

A third series of tests was performed to evaluate sorption of Tc-99 on to crushed cured binder samples and subsequent extraction of the sorbed Tc-99 from these samples. The sorption part of the test was performed according to a combination of the ASTM D-4646, 24-Hour Sorption Test, and ASTM D-4319, Short-Term Batch Sorption Test, protocols [12 and 13, respectively]. The desorption part of the test was performed on the binders after a total of 5 days exposure to the Tc99 spiked solutions, according to a modified ASTM D-5233 extraction test [11].

The non-radioactive binders, cured for at least 28 days, were crushed and sieved to -60 and +80 mesh. Three grams of the sieved material were weighed and placed in the $35 \mathrm{~mL}$ centrifuge tube leaching containers. The sorption part of the test was performed using the following solutions:

- DIW spiked with $1.52 \times 10^{-5} \mathrm{M}$ Tc-99,

- Tank C-106 post retrieval heel simulant spiked with $1.52 \times 10^{-5} \mathrm{M}$ Tc-99, and

- Tank C-200 Series average post retrieval heel simulant spiked with $1.46 \times 10^{-5} \mathrm{M}$ Tc-99.

See Table 3-5 for the ingredients in the simulants.

Small amounts of leachate were extracted from the centrifuge tubes with a syringe at each interval and filtered through a $0.045 \mu \mathrm{m}$ nylon filter. Duplicate $1-\mathrm{mL}$ samples of filtered leachate were collected for Tc-99 analysis. The sample configuration is illustrated in Figure 3-6.

The desorption part of the test was performed subsequent to the sorption testing using the binders from the sorption tests. Each 3-gram sample with sorbed Tc-99 was extracted/leached with the same solution as used for the sorption study but without Tc-99 (non-radioactive DIW, Tank C106 simulated heel or Tank C-200 series average simulated heel). Small amounts of each leachate were extracted from the centrifuge tubes with a syringe at each interval and filtered through a $0.045 \mu \mathrm{m}$ nylon filter. Duplicate 1-mL samples of each filtered leachate were collected and analyzed for Tc-99.

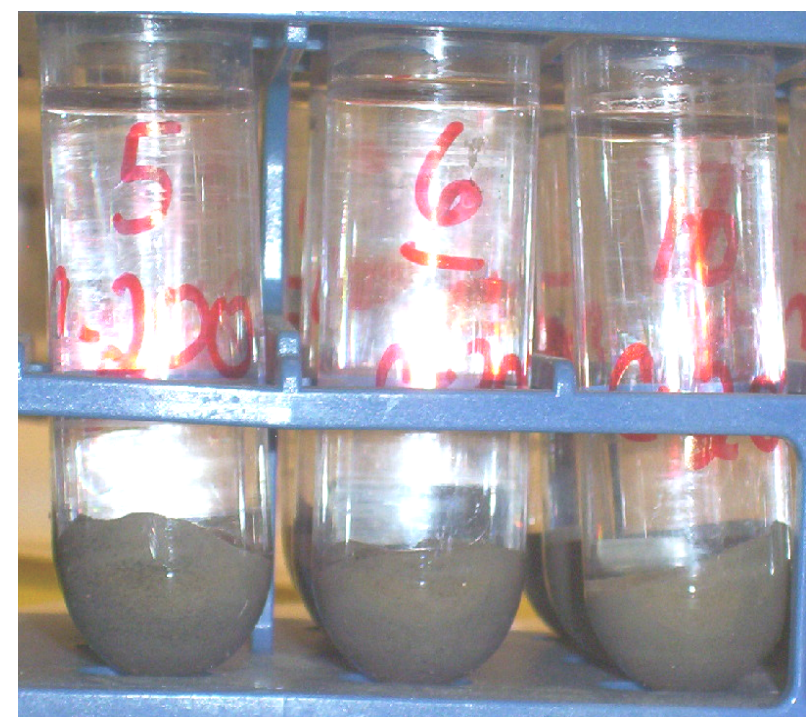

Figure 3-6. 3 grams of crushed sample in $30 \mathrm{~mL}$ of leachate. 


\subsection{RESULTS}

Monolithic samples spiked with Tc-99 were leached to obtain technetium leach rates for nondegraded tank fill grouts. Crushed samples spiked with Tc-99 were leached to estimate leach rates for physically degraded tank fill grouts. Since leaching is typically directly proportional to the sample surface area in contact with the leachate, the crushed samples also provide a means of accelerating the leaching process. Sorption/desorption tests were also performed to determine whether cured fill grout material retard migration of Tc-99.

Three different leachates (contact liquids) were used to simulate the following conditions:

1) Stabilization or leaching of grout in contact with Tank C-106 heel (Simulated C-106 supernate)

2) Stabilization or leaching of grout in contact with Tank C-200 heel (Simulated Tank C-200 average supernate)

3) Contact with infiltrating water in contact with cementitious fill grout (Approximated by C-106 simulant)

4) Contact with rainwater (DI water)

\subsection{ANSI/ANS-16.1 Monolith Leaching}

Six variations of a reducing grout binder (HRG 2) were spiked with Tc-99 at the time they were prepared and cast into monoliths. The compositions and physical characteristics of these six samples are provided in Section 3. An abbreviated ANSI 16.1 test was conducted to quantify the relative Tc-99 leach rates of each binder composition. Deionized water was used as the leachate in all of the ANSI/ANS 16.1 tests. Following an initial rinse of 30 seconds, leachate samples were taken at 2, 7, 24, 48, 120 and 624 hours.

Tc-99 leachate concentrations for each leaching interval are presented in Table 4-1. The uncertainties in the reported concentrations, as determined by SNL using their measurement protocol, are provided at the two-sigma level in Table 4-2. The high value was calculated by subtracting the $2 \sigma$ uncertainty from the measured Tc-99 concentration. The low value was calculated by adding the $2 \sigma$ uncertainty to the measured Tc- 99 concentration. A value of 0.01 was substituted for measured concentrations, $A_{n}$, for cases where the reported concentration was negative. The same value, 0.01 , was also substituted for negative high and low values, i.e., $+/-2 \sigma$ values. This value is somewhat arbitrary but is reasonable given that the measured values ranged from E+00 to E-02.

The monolithic sample leachate concentrations were used to calculate the following parameters:

1) Tc-99 effective diffusion coefficient from the measured values for each time interval.

2) Average Tc-99 effective diffusion coefficients (over time interval)

3) Tc-99 ANSI/ANS 16.1 Leach Indices.

In addition, high and low effective diffusivities and Leach Indices were calculated from the concentrations $+/-2 \sigma$. 
WSRC-TR-2004-00021, Rev. 0

January 12, 2004

Page 13 of 38

Table 4-1. Tc-99 leachate concentrations per the ANSI/ANS 16.1 protocol for six binders.

\begin{tabular}{|l|c|c|c|c|c|c|c|c|}
\hline \multirow{2}{*}{$\begin{array}{c}\text { Monolith } \\
\text { Description* } \\
\text { (Tc treatment reagent/ } \\
\text { Source of mixing water) }\end{array}$} & Sample & \multicolumn{2}{|c|}{ Tc-99 concentrations as a function of leach interval (pCi/mL) } \\
\cline { 3 - 10 } & $\mathbf{I D}$ & $\mathbf{3 0} \mathbf{~ s e c}$ & $\mathbf{2} \mathbf{~ h r}$ & $\mathbf{7 ~ h r}$ & $\mathbf{2 4} \mathbf{~ h r}$ & $\mathbf{4 8} \mathbf{~ h r}$ & $\mathbf{1 2 0} \mathbf{~ h r}$ & $\mathbf{6 2 4} \mathbf{~ h r}$ \\
\hline Slag/DI & 12 & $6.75 \mathrm{E}-01$ & $1.09 \mathrm{E}+00$ & $4.53 \mathrm{E}-01$ & $1.51 \mathrm{E}+00$ & $6.75 \mathrm{E}-01$ & $5.45 \mathrm{E}-01$ & $-1.40 \mathrm{E}+00$ \\
\hline Slag/DI & $12 \mathrm{~B}$ & $3.37 \mathrm{E}-01$ & $1.48 \mathrm{E}+00$ & $1.96 \mathrm{E}+00$ & $6.12 \mathrm{E}-01$ & $5.97 \mathrm{E}-01$ & $8.34 \mathrm{E}-01$ & $-3.38 \mathrm{E}-02$ \\
\hline Slag/C-106 & 13 & $1.67 \mathrm{E}+00$ & $2.75 \mathrm{E}-01$ & $4.82 \mathrm{E}-01$ & $8.67 \mathrm{E}-01$ & $3.71 \mathrm{E}-01$ & $9.64 \mathrm{E}-01$ & $-6.27 \mathrm{E}-02$ \\
\hline Slag/C-106 & $13 \mathrm{~B}$ & $-1.45 \mathrm{E}-01$ & $5.64 \mathrm{E}-01$ & $6.60 \mathrm{E}-01$ & $1.08 \mathrm{E}+00$ & $1.86 \mathrm{E}+00$ & $-2.26 \mathrm{E}-01$ & $7.23 \mathrm{E}-01$ \\
\hline Slag + Apatite/DI & 14 & $1.32 \mathrm{E}+00$ & $3.79 \mathrm{E}+00$ & $9.83 \mathrm{E}-01$ & $3.46 \mathrm{E}+00$ & $5.49 \mathrm{E}-01$ & $1.47 \mathrm{E}+00$ & $-3.86 \mathrm{E}-01$ \\
\hline Slag + Apatite/DI & $14 \mathrm{~B}$ & $9.16 \mathrm{E}-01$ & $1.75 \mathrm{E}+00$ & $1.37 \mathrm{E}+00$ & $1.45 \mathrm{E}+00$ & $9.83 \mathrm{E}-01$ & $-3.57 \mathrm{E}-01$ & $-1.93 \mathrm{E}-01$ \\
\hline Slag + Apatite/C-106 & 15 & $7.08 \mathrm{E}-01$ & $1.06 \mathrm{E}+00$ & $1.51 \mathrm{E}+00$ & $1.77 \mathrm{E}+00$ & $7.90 \mathrm{E}+00$ & $8.48 \mathrm{E}-01$ & $-1.30 \mathrm{E}-01$ \\
\hline Slag + Apatite/C-106 & $15 \mathrm{~B}$ & $-9.64 \mathrm{E}-02$ & $1.69 \mathrm{E}+00$ & $1.83 \mathrm{E}+00$ & $1.80 \mathrm{E}+00$ & $6.26 \mathrm{E}-01$ & $9.64 \mathrm{E}-01$ & $-6.90 \mathrm{E}-01$ \\
\hline Slag/C-200 & 16 & $1.05 \mathrm{E}+00$ & $1.20 \mathrm{E}+00$ & $1.56 \mathrm{E}+00$ & $1.20 \mathrm{E}+00$ & $1.33 \mathrm{E}+00$ & $1.83 \mathrm{E}+00$ & $-6.75 \mathrm{E}-01$ \\
\hline Slag/C-200 & $16 \mathrm{~B}$ & $9.97 \mathrm{E}-01$ & $9.83 \mathrm{E}-01$ & $7.23 \mathrm{E}-01$ & $2.38 \mathrm{E}+00$ & $7.23 \mathrm{E}-01$ & $1.52 \mathrm{E}+00$ & $-4.20 \mathrm{E}-01$ \\
\hline Slag + Apatite/C-200 & 17 & $8.87 \mathrm{E}-01$ & $1.88 \mathrm{E}+00$ & $1.09 \mathrm{E}+00$ & $7.57 \mathrm{E}-01$ & $9.83 \mathrm{E}-01$ & $2.41 \mathrm{E}-01$ & $-5.45 \mathrm{E}-01$ \\
\hline Slag + Apatite/C-200 & $17 \mathrm{~B}$ & $7.23 \mathrm{E}-01$ & $1.29 \mathrm{E}+00$ & $1.80 \mathrm{E}+00$ & $2.04 \mathrm{E}+00$ & $5.16 \mathrm{E}-01$ & $1.35 \mathrm{E}+00$ & $0.00 \mathrm{E}+00$ \\
\hline
\end{tabular}

*All samples contained slag as a Tc-99 stabilizing reagent. Some samples also contained surface treated hydroxyapatite. The liquid phase used to make the grout, i.e., phase that contributed the mixing water, is also indicated as DI, deionized water, simulated C-106 heel, or simulated C-200 series heel.

Table 4-2. Uncertainties in the Tc-99 leachate concentrations for each time interval at the two-sigma level.

\begin{tabular}{|c|c|c|c|c|c|c|c|c|}
\hline \multirow{2}{*}{$\begin{array}{c}\text { Monolith } \\
\text { Description* } \\
\text { (Tc treatment reagent/ } \\
\text { Source of mixing water) }\end{array}$} & \multirow{2}{*}{$\begin{array}{c}\text { Sample } \\
\text { ID }\end{array}$} & \multicolumn{7}{|c|}{2 Sigma Error in Tc-99 concentrations for each leach interval } \\
\hline & & 30 Seconds & 2 hours & 7 hours & 24 hours & 48 hours & 120 hours & 624 hours \\
\hline Slag/DI & 12 & $1.32 \mathrm{E}+00$ & $1.37 \mathrm{E}+00$ & $1.29 \mathrm{E}+00$ & $1.42 \mathrm{E}+00$ & $1.36 \mathrm{E}+00$ & $1.36 \mathrm{E}+00$ & $1.42 \mathrm{E}+00$ \\
\hline Slag/DI & 12B & $1.28 \mathrm{E}+00$ & $1.41 \mathrm{E}+00$ & $1.47 \mathrm{E}+00$ & $1.31 \mathrm{E}+00$ & $1.35 \mathrm{E}+00$ & $1.39 \mathrm{E}+00$ & $1.33 \mathrm{E}+00$ \\
\hline Slag/C-106 & 13 & $1.43 \mathrm{E}+00$ & $1.27 \mathrm{E}+00$ & $1.30 \mathrm{E}+00$ & $1.34 \mathrm{E}+00$ & $1.33 \mathrm{E}+00$ & $1.31 \mathrm{E}+00$ & $1.33 \mathrm{E}+00$ \\
\hline Slag/C-106 & $13 \mathrm{~B}$ & $1.25 \mathrm{E}+00$ & $1.31 \mathrm{E}+00$ & $1.32 \mathrm{E}+00$ & $1.37 \mathrm{E}+00$ & $1.50 \mathrm{E}+00$ & $1.31 \mathrm{E}+00$ & $1.41 \mathrm{E}+00$ \\
\hline Slag + Apatite/DI & 14 & $1.39 \mathrm{E}+00$ & $1.67 \mathrm{E}+00$ & $1.35 \mathrm{E}+00$ & $1.64 \mathrm{E}+00$ & $1.35 \mathrm{E}+00$ & $1.46 \mathrm{E}+00$ & $1.35 \mathrm{E}+00$ \\
\hline Slag + Apatite/DI & 14B & $1.35 \mathrm{E}+00$ & $1.44 \mathrm{E}+00$ & $1.40 \mathrm{E}+00$ & $1.41 \mathrm{E}+00$ & $1.40 \mathrm{E}+00$ & $1.32 \mathrm{E}+00$ & $1.34 \mathrm{E}+00$ \\
\hline Slag + Apatite/C-106 & 15 & $1.32 \mathrm{E}+00$ & $1.36 \mathrm{E}+00$ & $1.42 \mathrm{E}+00$ & $1.44 \mathrm{E}+00$ & $1.38 \mathrm{E}+00$ & $1.39 \mathrm{E}+00$ & $1.33 \mathrm{E}+00$ \\
\hline Slag + Apatite/C-106 & 15B & $1.25 \mathrm{E}+00$ & $1.44 \mathrm{E}+00$ & $1.45 \mathrm{E}+00$ & $1.45 \mathrm{E}+00$ & $1.36 \mathrm{E}+00$ & $1.41 \mathrm{E}+00$ & $1.37 \mathrm{E}+00$ \\
\hline Slag/C-200 & 16 & $1.36 \mathrm{E}+00$ & $1.38 \mathrm{E}+00$ & $1.42 \mathrm{E}+00$ & $1.38 \mathrm{E}+00$ & $1.44 \mathrm{E}+00$ & $1.50 \mathrm{E}+00$ & $1.37 \mathrm{E}+00$ \\
\hline Slag/C-200 & $16 \mathrm{~B}$ & $1.36 \mathrm{E}+00$ & $1.35 \mathrm{E}+00$ & $1.33 \mathrm{E}+00$ & $1.51 \mathrm{E}+00$ & $1.37 \mathrm{E}+00$ & $1.47 \mathrm{E}+00$ & $1.35 \mathrm{E}+00$ \\
\hline Slag + Apatite/C-200 & 17 & $1.34 \mathrm{E}+00$ & $1.46 \mathrm{E}+00$ & $1.37 \mathrm{E}+00$ & $1.33 \mathrm{E}+00$ & $1.40 \mathrm{E}+00$ & $1.32 \mathrm{E}+00$ & $1.36 \mathrm{E}+00$ \\
\hline Slag + Apatite/C-200 & 17B & $1.32 \mathrm{E}+00$ & $1.39 \mathrm{E}+00$ & $1.45 \mathrm{E}+00$ & $1.48 \mathrm{E}+00$ & $1.35 \mathrm{E}+00$ & $1.45 \mathrm{E}+00$ & $1.33 \mathrm{E}+00$ \\
\hline
\end{tabular}

*All samples contained slag as a Tc-99 stabilizing reagent. Some samples also contained surface treated hydroxyapatite. The liquid phase used to make the grout, i.e., phase that contributed the mixing water, is also indicated as DI, deionized water, simulated C-106 heel, or simulated C-200 series heel. 


\subsubsection{Effective Diffusion Coefficients}

Tc-99 effective diffusivities were calculated for each binder according to Equation 1 and are listed for each leach interval in Table 4-3. Diffusivities were also calculated for the $+/-2 \sigma$ uncertainty levels (i.e., at $\sim 95 \%$ confidence level). See Table $4-3$. High values were calculated by subtracting the $2 \sigma$ uncertainty from the measured Tc- 99 concentrations. Low value was calculated by adding the $2 \sigma$ uncertainties to the measured Tc- 99 concentrations. A value of 0.01 was substituted for $A_{n}$ for cases where the measured concentration or the concentration $+/-2 \sigma$ was reported as a negative value. Average effective diffusion coefficients were calculated according to Equation 2 for all of these cases and are also listed in Table 4-3.

Equation 1: $\mathbf{D}=\Pi\left[\frac{\bullet_{\mathrm{n}} / \bullet_{0}}{(\Delta t)_{\mathrm{n}}}\right]^{\mathbf{2}}\left[\frac{V}{S}\right]^{\mathbf{2}} \mathbf{T}$

Where:

$\mathrm{D}=$ effective diffusivity, $\mathrm{cm}^{2} / \mathrm{sec}$,

$\mathrm{V}=$ volume of specimen, $\mathrm{cm}^{3}$,

$\mathrm{S}=$ geometric surface area of the specimen calculated from measured dimensions, $\mathrm{cm}^{2}$,

$\mathrm{T}=$ leaching time representing the mean time of the leaching interval, $\mathrm{s}$,

$\mathrm{A}_{\mathrm{n}}=$ activity of Tc-99 released from the specimen during leaching interval $\mathrm{n}$ (no correction for radioactive decay for Tc-99),

$\mathrm{A}_{0}=$ total activity of a given radionuclide in the specimen at the beginning of the first leaching interval (after the 30-s rinse) and

$(\Delta \mathrm{t})_{\mathrm{n}}=\mathrm{t}_{\mathrm{n}}-\mathrm{t}_{\mathrm{n}-1}$, duration of the $\mathrm{nth}$ leaching interval, $\mathrm{s}$

Equation 2: $\quad D_{\text {ave }}=1 / 6 \sum_{1}^{6} D_{i}$

\subsubsection{Leach Indices}

Leaching Indices were calculated for each binder using Equation 3 per the abbreviated ANSI/ANS 16.1 protocol. See Table 4-4. Leachability Indices were also calculated for the +/$2 \sigma$ uncertainty levels (i.e., at $\sim 95 \%$ confidence level). See Table $4-4$. The high value was calculated by subtracting the $2 \sigma$ uncertainty from the measured Tc- 99 concentration. The low value was calculated by adding the $2 \sigma$ uncertainty to the measured Tc- 99 concentration. A value of 0.01 was substituted for $A_{n}$ for cases where the measured concentration or the concentration +/$2 \sigma$ was negative.

Equation 3: $\mathbf{L}=\mathbf{1 / 6} \sum_{1}^{6}[\log (\beta / \mathrm{Di})]_{\mathbf{n}}$

Where:

$\mathrm{L}=$ Leachability Index for Tc-99 as determined from the abbreviated test,

$\beta=$ defined constant $\left(1.0 \mathrm{~cm}^{2} / \mathrm{sec}\right)$,

$\mathrm{Di}=$ effective diffusivity of the nuclide Tc-99 calculated from the test data. 
WSRC-TR-2004-00021, Rev. 0 January 12, 2004

Page 15 of 38

Table 4-3. Effective diffusion coefficients for six binder compositions.

\begin{tabular}{|c|c|c|c|c|c|c|c|c|c|}
\hline \multirow{2}{*}{\multicolumn{2}{|c|}{ Leach Interval }} & \multicolumn{7}{|c|}{ Nominal Effective Diffusion coefficients $\left(\mathrm{cm}^{2} / \mathrm{sec}\right)$} & \multirow{2}{*}{$\begin{array}{l}\text { Leach } \\
\text { Index }\end{array}$} \\
\hline & & 1 & 2 & 3 & 4 & 5 & 6 & Average & \\
\hline \multirow{12}{*}{ Sample ID } & 12 & $1.74 \mathrm{E}-10$ & $3.96 \mathrm{E}-11$ & $2.24 \mathrm{E}-10$ & $5.52 \mathrm{E}-11$ & $9.15 \mathrm{E}-12$ & $2.54 \mathrm{E}-16$ & 8.37E-11 & 11.1 \\
\hline & $12 b$ & $3.21 \mathrm{E}-10$ & $7.42 \mathrm{E}-10$ & $3.68 \mathrm{E}-11$ & 4.32E-11 & $2.14 \mathrm{E}-11$ & $2.54 \mathrm{E}-16$ & $1.94 \mathrm{E}-10$ & 10.9 \\
\hline & 13 & $1.28 \mathrm{E}-11$ & $5.20 \mathrm{E}-11$ & $8.50 \mathrm{E}-11$ & $1.92 \mathrm{E}-11$ & $3.29 \mathrm{E}-11$ & $2.84 \mathrm{E}-16$ & $3.36 \mathrm{E}-11$ & 11.3 \\
\hline & $13 \mathrm{~b}$ & $5.40 \mathrm{E}-11$ & $9.75 \mathrm{E}-11$ & $1.32 \mathrm{E}-10$ & $4.82 \mathrm{E}-10$ & $3.54 \mathrm{E}-15$ & $1.48 \mathrm{E}-12$ & $1.28 \mathrm{E}-10$ & 11.0 \\
\hline & 14 & $2.38 \mathrm{E}-09$ & $2.11 \mathrm{E}-10$ & $1.32 \mathrm{E}-09$ & 4.10E-11 & $7.46 \mathrm{E}-11$ & $2.77 \mathrm{E}-16$ & $6.71 \mathrm{E}-10$ & 10.5 \\
\hline & $14 \mathrm{~b}$ & $5.07 \mathrm{E}-10$ & $4.10 \mathrm{E}-10$ & $2.32 \mathrm{E}-10$ & $1.31 \mathrm{E}-10$ & $3.45 \mathrm{E}-15$ & $2.77 \mathrm{E}-16$ & $2.13 \mathrm{E}-10$ & 11.4 \\
\hline & 15 & $2.22 \mathrm{E}-10$ & $5.95 \mathrm{E}-10$ & $4.16 \mathrm{E}-10$ & $1.02 \mathrm{E}-08$ & $2.99 \mathrm{E}-11$ & $3.43 \mathrm{E}-16$ & $1.92 \mathrm{E}-09$ & 10.4 \\
\hline & $15 b$ & $5.65 \mathrm{E}-10$ & $8.74 \mathrm{E}-10$ & $4.31 \mathrm{E}-10$ & $6.42 \mathrm{E}-11$ & $3.87 \mathrm{E}-11$ & $3.43 \mathrm{E}-16$ & $3.29 \mathrm{E}-10$ & 10.6 \\
\hline & 16 & $2.87 \mathrm{E}-10$ & $6.40 \mathrm{E}-10$ & $1.97 \mathrm{E}-10$ & $2.98 \mathrm{E}-10$ & $1.43 \mathrm{E}-10$ & $3.75 \mathrm{E}-16$ & $2.61 \mathrm{E}-10$ & 10.5 \\
\hline & $16 \mathrm{~b}$ & $1.93 \mathrm{E}-10$ & $1.37 \mathrm{E}-10$ & $7.73 \mathrm{E}-10$ & $8.80 \mathrm{E}-11$ & $9.88 \mathrm{E}-11$ & $3.75 \mathrm{E}-16$ & $2.15 \mathrm{E}-10$ & 10.7 \\
\hline & 17 & $7.91 \mathrm{E}-10$ & $3.51 \mathrm{E}-10$ & $8.78 \mathrm{E}-11$ & $1.83 \mathrm{E}-10$ & $2.79 \mathrm{E}-12$ & $4.21 \mathrm{E}-16$ & $2.36 \mathrm{E}-10$ & 10.9 \\
\hline & $17 \mathrm{~b}$ & $3.72 \mathrm{E}-10$ & $9.56 \mathrm{E}-10$ & $6.38 \mathrm{E}-10$ & $5.03 \mathrm{E}-11$ & $8.75 \mathrm{E}-11$ & $4.21 \mathrm{E}-16$ & $3.51 \mathrm{E}-10$ & 10.6 \\
\hline \multirow{2}{*}{\multicolumn{2}{|c|}{ Leach Interval }} & \multicolumn{7}{|c|}{ Low Effective Diffusion coefficients $\left(\mathrm{cm}^{2} / \mathrm{sec}\right)$} & Leach \\
\hline & & 1 & 2 & 3 & 4 & 5 & 6 & Average & Index \\
\hline \multirow{12}{*}{ Sample ID } & 12 & $1.46 \mathrm{E}-14$ & $1.93 \mathrm{E}-14$ & $7.96 \mathrm{E}-13$ & $1.21 \mathrm{E}-14$ & $3.08 \mathrm{E}-15$ & $2.54 \mathrm{E}-16$ & $1.41 \mathrm{E}-13$ & 13.9 \\
\hline & $12 b$ & $7.17 \mathrm{E}-13$ & $4.63 \mathrm{E}-11$ & $9.83 \mathrm{E}-15$ & $1.21 \mathrm{E}-14$ & $3.08 \mathrm{E}-15$ & $2.54 \mathrm{E}-16$ & $7.85 \mathrm{E}-12$ & 13.4 \\
\hline & 13 & $1.70 \mathrm{E}-14$ & $2.24 \mathrm{E}-14$ & $1.13 \mathrm{E}-14$ & $1.39 \mathrm{E}-14$ & $3.54 \mathrm{E}-15$ & $2.84 \mathrm{E}-16$ & $1.14 \mathrm{E}-14$ & 14.2 \\
\hline & $13 \mathrm{~b}$ & $1.70 \mathrm{E}-14$ & $2.24 \mathrm{E}-14$ & $1.13 \mathrm{E}-14$ & $1.81 \mathrm{E}-11$ & $3.54 \mathrm{E}-15$ & $2.84 \mathrm{E}-16$ & $3.02 \mathrm{E}-12$ & 13.7 \\
\hline & 14 & $7.44 \mathrm{E}-10$ & $2.18 \mathrm{E}-14$ & $3.65 \mathrm{E}-10$ & $1.36 \mathrm{E}-14$ & $3.45 \mathrm{E}-15$ & $2.77 \mathrm{E}-16$ & $1.85 \mathrm{E}-10$ & 12.7 \\
\hline & $14 \mathrm{~b}$ & $1.59 \mathrm{E}-11$ & $2.18 \mathrm{E}-14$ & $1.76 \mathrm{E}-13$ & $1.36 \mathrm{E}-14$ & $3.45 \mathrm{E}-15$ & $2.77 \mathrm{E}-16$ & $2.69 \mathrm{E}-12$ & 13.5 \\
\hline & 15 & $1.98 \mathrm{E}-14$ & $2.11 \mathrm{E}-12$ & $1.45 \mathrm{E}-11$ & $6.97 \mathrm{E}-09$ & $4.16 \mathrm{E}-15$ & $3.43 \mathrm{E}-16$ & $1.16 \mathrm{E}-09$ & 12.4 \\
\hline & $15 b$ & $1.24 \mathrm{E}-11$ & $3.77 \mathrm{E}-11$ & $1.63 \mathrm{E}-11$ & $1.64 \mathrm{E}-14$ & $4.16 \mathrm{E}-15$ & $3.43 \mathrm{E}-16$ & $1.11 \mathrm{E}-11$ & 12.6 \\
\hline & 16 & $1.99 \mathrm{E}-14$ & $5.15 \mathrm{E}-12$ & $1.36 \mathrm{E}-14$ & $1.68 \mathrm{E}-14$ & $4.65 \mathrm{E}-12$ & $3.75 \mathrm{E}-16$ & $1.64 \mathrm{E}-12$ & 13.2 \\
\hline & $16 \mathrm{~b}$ & $1.99 \mathrm{E}-14$ & $2.63 \mathrm{E}-14$ & $1.03 \mathrm{E}-10$ & $1.68 \mathrm{E}-14$ & $1.07 \mathrm{E}-13$ & $3.75 \mathrm{E}-16$ & $1.72 \mathrm{E}-11$ & 13.2 \\
\hline & 17 & $3.95 \mathrm{E}-11$ & $2.95 \mathrm{E}-14$ & $1.53 \mathrm{E}-14$ & $1.89 \mathrm{E}-14$ & $4.80 \mathrm{E}-15$ & $4.21 \mathrm{E}-16$ & $6.59 \mathrm{E}-12$ & 13.5 \\
\hline & $17 \mathrm{~b}$ & $2.24 \mathrm{E}-14$ & $3.62 \mathrm{E}-11$ & $4.81 \mathrm{E}-11$ & $1.89 \mathrm{E}-14$ & $4.80 \mathrm{E}-15$ & $4.21 \mathrm{E}-16$ & $1.40 \mathrm{E}-11$ & 13.0 \\
\hline \multirow{2}{*}{\multicolumn{2}{|c|}{ Leach Interval }} & \multicolumn{7}{|c|}{ High Effective Diffusion coefficients $\left(\mathrm{cm}^{2} / \mathrm{sec}\right)$} & Leach \\
\hline & & 1 & 2 & 3 & 4 & 5 & 6 & Average & Index \\
\hline \multirow{12}{*}{ Sample ID } & 12 & $8.86 \mathrm{E}-10$ & $5.86 \mathrm{E}-10$ & $8.44 \mathrm{E}-10$ & $5.02 \mathrm{E}-10$ & $1.12 \mathrm{E}-10$ & $1.02 \mathrm{E}-15$ & $4.88 \mathrm{E}-10$ & 10.3 \\
\hline & $12 \mathrm{~b}$ & $1.22 \mathrm{E}-09$ & 2.27E-09 & $3.63 \mathrm{E}-10$ & $4.60 \mathrm{E}-10$ & $1.52 \mathrm{E}-10$ & $4.26 \mathrm{E}-12$ & $7.45 \mathrm{E}-10$ & 9.6 \\
\hline & 13 & $4.05 \mathrm{E}-10$ & $7.11 \mathrm{E}-10$ & $5.51 \mathrm{E}-10$ & $4.03 \mathrm{E}-10$ & $1.83 \mathrm{E}-10$ & $4.56 \mathrm{E}-12$ & $3.76 \mathrm{E}-10$ & 9.7 \\
\hline & $13 b$ & $5.96 \mathrm{E}-10$ & $8.77 \mathrm{E}-10$ & $6.78 \mathrm{E}-10$ & $1.57 \mathrm{E}-09$ & $4.16 \mathrm{E}-11$ & $1.29 \mathrm{E}-11$ & $6.30 \mathrm{E}-10$ & 9.6 \\
\hline & 14 & 4.93E-09 & 1.19E-09 & $2.87 \mathrm{E}-09$ & $4.90 \mathrm{E}-10$ & $2.96 \mathrm{E}-10$ & $2.57 \mathrm{E}-12$ & $1.63 \mathrm{E}-09$ & 9.4 \\
\hline & $14 \mathrm{~b}$ & $1.68 \mathrm{E}-09$ & $1.67 \mathrm{E}-09$ & $9.02 \mathrm{E}-10$ & $7.72 \mathrm{E}-10$ & $3.20 \mathrm{E}-11$ & $3.64 \mathrm{E}-12$ & $8.45 \mathrm{E}-10$ & 9.6 \\
\hline & 15 & $1.16 \mathrm{E}-09$ & $2.24 \mathrm{E}-09$ & $1.37 \mathrm{E}-09$ & $1.41 \mathrm{E}-08$ & $2.08 \mathrm{E}-10$ & 4.94E-12 & $3.18 \mathrm{E}-09$ & 9.2 \\
\hline & $15 \mathrm{~b}$ & $1.94 \mathrm{E}-09$ & $2.81 \mathrm{E}-09$ & $1.40 \mathrm{E}-09$ & $6.46 \mathrm{E}-10$ & $2.35 \mathrm{E}-10$ & $1.59 \mathrm{E}-12$ & 1.17E-09 & 9.5 \\
\hline & 16 & 1.33E-09 & $2.33 \mathrm{E}-09$ & $9.08 \mathrm{E}-10$ & $1.29 \mathrm{E}-09$ & $4.74 \mathrm{E}-10$ & $1.81 \mathrm{E}-12$ & $1.06 \mathrm{E}-09$ & 9.4 \\
\hline & $16 \mathrm{~b}$ & $1.08 \mathrm{E}-09$ & $1.11 \mathrm{E}-09$ & $2.07 \mathrm{E}-09$ & 7.37E-10 & $3.82 \mathrm{E}-10$ & $3.24 \mathrm{E}-12$ & $8.97 \mathrm{E}-10$ & 9.4 \\
\hline & 17 & $2.50 \mathrm{E}-09$ & $1.79 \mathrm{E}-09$ & $6.68 \mathrm{E}-10$ & $1.07 \mathrm{E}-09$ & $1.17 \mathrm{E}-10$ & $2.79 \mathrm{E}-12$ & $1.02 \mathrm{E}-09$ & 9.5 \\
\hline & $17 \mathrm{~b}$ & $1.61 \mathrm{E}-09$ & $3.12 \mathrm{E}-09$ & $1.90 \mathrm{E}-09$ & $6.58 \mathrm{E}-10$ & $3.76 \mathrm{E}-10$ & 7.44E-12 & $1.28 \mathrm{E}-09$ & 9.3 \\
\hline
\end{tabular}


WSRC-TR-2004-00021, Rev. 0

January 12, 2004

Page 16 of 38

Table 4-4. Leach Indices for six binder compositions.

\begin{tabular}{|c|c|c|c|c|}
\hline \multirow{2}{*}{$\begin{array}{l}\text { Monolith Description } \\
\text { (Tc treatment reagent/ } \\
\text { Source of mixing water) }\end{array}$} & \multirow[b]{2}{*}{ Sample No. } & \multicolumn{3}{|c|}{ Leachability Indices } \\
\hline & & $\begin{array}{c}\text { High } \\
{[\text { Measured - 2 }]}\end{array}$ & $\begin{array}{c}\text { Actual } \\
\text { [Measured] }\end{array}$ & $\begin{array}{c}\text { Low } \\
{[\text { Measured }+2 \sigma]}\end{array}$ \\
\hline Slag/DI & 12 & 14.0 & 11.1 & 10.3 \\
\hline Slag/DI & $12 \mathrm{~b}$ & 13.4 & 11.0 & 9.6 \\
\hline Slag/C-106 & 13 & 14.2 & 11.3 & 9.7 \\
\hline Slag/C-106 & $13 \mathrm{~b}$ & 13.7 & 11.0 & 9.6 \\
\hline Slag + Apatite/DI & 14 & 12.7 & 10.5 & 9.4 \\
\hline Slag + Apatite/DI & $14 \mathrm{~b}$ & 13.5 & 11.4 & 9.6 \\
\hline Slag + Apatite/C-106 & 15 & 12.4 & 10.4 & 9.2 \\
\hline Slag + Apatite/C-106 & $15 \mathrm{~b}$ & 12.6 & 10.6 & 9.5 \\
\hline Slag/C-200 & 16 & 13.2 & 10.5 & 9.4 \\
\hline Slag/C-200 & $16 b$ & 13.2 & 10.7 & 9.4 \\
\hline Slag + Apatite/C-200 & 17 & 13.5 & 10.9 & 9.5 \\
\hline Slag + Apatite/C-200 & $17 \mathrm{~b}$ & 13.0 & 10.6 & 9.3 \\
\hline
\end{tabular}

\subsection{Leaching Crushed Binders}

Duplicate three-grams binder sample spiked with Tc-99 were crushed and leached in $30 \mathrm{~mL}$ of DI water. Crushing was intended to simulate the effects of physical degradation that typically assumed in aging models. In addition, crushing was intended to accentuate differences between the samples since surface area is directly related to leaching.

The Tc-99 leachate concentrations were measured at 1, 5, and 27 days. The results are presented in Table 4-5. The maximum amount of Tc-99 leached during any single leach interval for each binder sample is listed in Table 4-6 as a percent of the total in the sample. Since the other leach intervals had lower concentrations, comparing concentrations for the interval with the maximum leachate concentration is a way of comparing the ability of the various binders to retard Tc-99 release. The slag and slag plus HA binders containing Tc-99 retained the most Tc after 27 days of leaching.

\subsection{Crushed versus monolithic results}

The differences between leaching monolithic and crushed binders are illustrated in Figure 4-1 for binders 12 to 14 and Figure 4-2 for binders 15 to 17 . As expected, significantly more Tc-99 was leached form the crushed samples compared to the monoliths. Tc-99 concentrations in the initial leach intervals accounted for the highest releases. Tc-99 concentrations in subsequent leachates generally decreased indicating that the Tc-99 was resorbed/restabilized. However, the crushed binders made with simulated C-200 series heel, did not show statistically significant Tc-99 resorption. 
WSRC-TR-2004-00021, Rev. 0

January 12, 2004

Page 17 of 38

Table 4-5. Tc-99 leachate concentrations for crushed binders as a function of time.

\begin{tabular}{|c|c|c|c|c|}
\hline \multirow{2}{*}{\begin{tabular}{|l|} 
Crushed Sample \\
Description \\
(Tc treatment reagent/ \\
Source of mixing water) \\
\end{tabular}} & \multirow{2}{*}{$\begin{array}{l}\text { Crushed } \\
\text { Sample } \\
\text { ID }\end{array}$} & \multicolumn{3}{|c|}{$\begin{array}{l}\text { Tc-99 concentrations as a function of leach time } \\
\qquad(\mathrm{pCi} / \mathrm{mL})\end{array}$} \\
\hline & & 24 hours & 120 hours & 648 hours \\
\hline & Blank & $9.64 \mathrm{E}-02$ & $1.01 \mathrm{E}+00$ & $9.65 \mathrm{E}-01$ \\
\hline Slag/DI & 12 & $6.44 \mathrm{E}+00$ & $6.17 \mathrm{E}+00$ & $2.89 \mathrm{E}+00$ \\
\hline Slag/DI & $12 \mathrm{~B}$ & $1.10 \mathrm{E}+01$ & $6.09 \mathrm{E}+00$ & $2.91 \mathrm{E}+00$ \\
\hline Slag/C-106 & 13 & $3.85 \mathrm{E}+01$ & $4.94 \mathrm{E}+01$ & $2.07 \mathrm{E}+01$ \\
\hline Slag/C-106 & $13 \mathrm{~B}$ & $3.79 \mathrm{E}+01$ & $4.01 \mathrm{E}+01$ & $2.07 \mathrm{E}+00$ \\
\hline Slag + Apatite/DI & 14 & $9.14 \mathrm{E}+00$ & $7.66 \mathrm{E}+00$ & $3.14 \mathrm{E}+00$ \\
\hline Slag + Apatite/DI & 14B & $5.48 \mathrm{E}+00$ & $8.93 \mathrm{E}+00$ & $2.16 \mathrm{E}+00$ \\
\hline Slag + Apatite/C-106 & 15 & $1.03 \mathrm{E}+00$ & $1.44 \mathrm{E}+01$ & $7.44 \mathrm{E}+00$ \\
\hline Slag + Apatite/C-106 & $15 \mathrm{~B}$ & $9.72 \mathrm{E}+00$ & $1.71 \mathrm{E}+00$ & $7.43 \mathrm{E}+00$ \\
\hline Slag/C-200 & 16 & $2.62 \mathrm{E}+01$ & $3.89 \mathrm{E}+01$ & $3.08 \mathrm{E}+01$ \\
\hline Slag/C-200 & $16 \mathrm{~B}$ & $1.85 \mathrm{E}+01$ & $3.34 \mathrm{E}+01$ & $3.48 \mathrm{E}+01$ \\
\hline Slag + Apatite/C-200 & 17 & $2.76 \mathrm{E}+01$ & $3.61 \mathrm{E}+01$ & $2.41 \mathrm{E}+01$ \\
\hline Slag + Apatite/C-200 & 17B & $2.22 \mathrm{E}+01$ & $3.01 \mathrm{E}+01$ & $2.84 \mathrm{E}+01$ \\
\hline
\end{tabular}

Table 4-6. Maximum amount of Tc-99 extracted from the crushed samples in any one leach interval in deionized water (expressed as a percentage of the total sorbed on each sample).

\begin{tabular}{|l|c|c|}
\hline $\begin{array}{l}\text { Crushed Sample Description } \\
\text { (Tc treatment reagent/Source of mixing } \\
\text { water) }\end{array}$ & $\begin{array}{c}\text { Sample } \\
\text { ID }\end{array}$ & $\begin{array}{l}\text { Maximum \% Tc-99 Extracted for } \\
\text { any single interval in DIW }\end{array}$ \\
\hline Slag/DI & 12 & 3 \\
\hline Slag/C-106 & 13 & 14 \\
\hline Slag + Apatite/DI & 14 & 3 \\
\hline Slag + Apatite/C-106 & 15 & 4 \\
\hline Slag/C-200 & 16 & 12 \\
\hline Slag + Apatite/C-200 & 17 & 11 \\
\hline
\end{tabular}


WSRC-TR-2004-00021, Rev. 0

January 12, 2004

Page 18 of 38

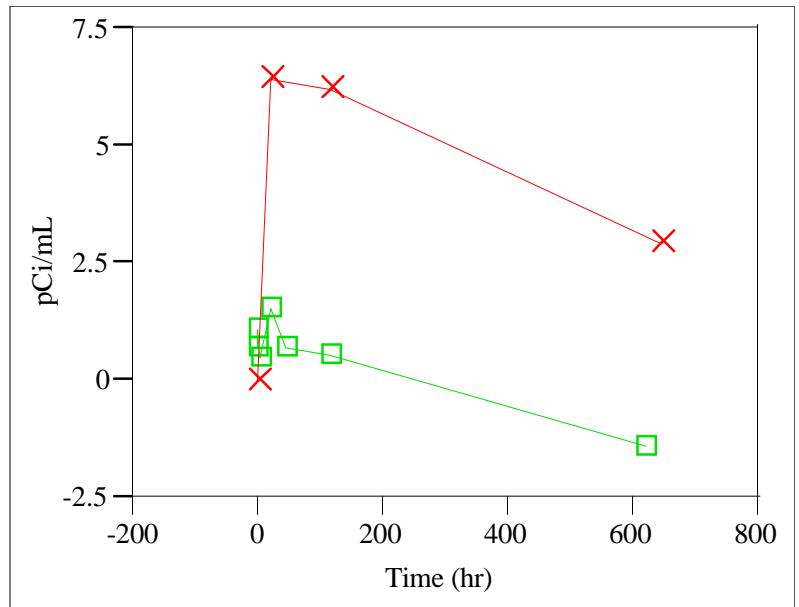

Sample ID=12

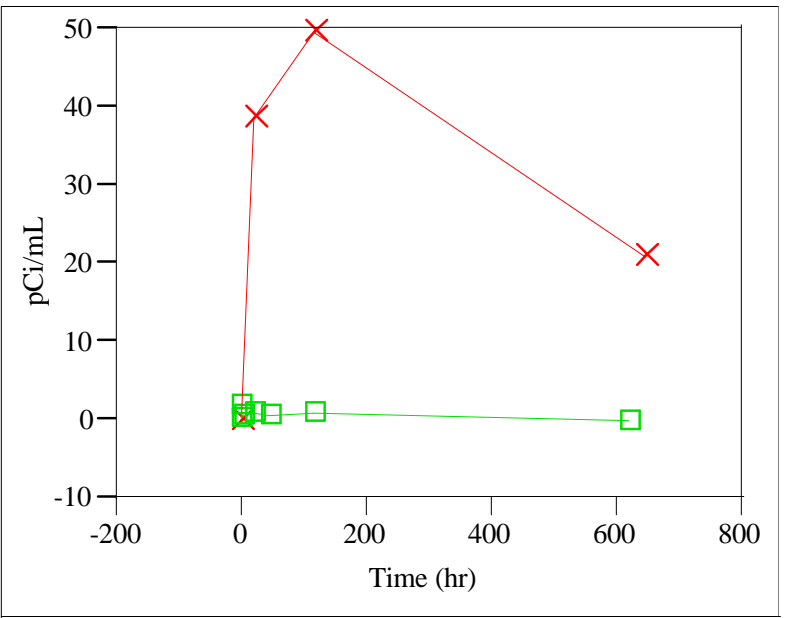

Sample ID=13

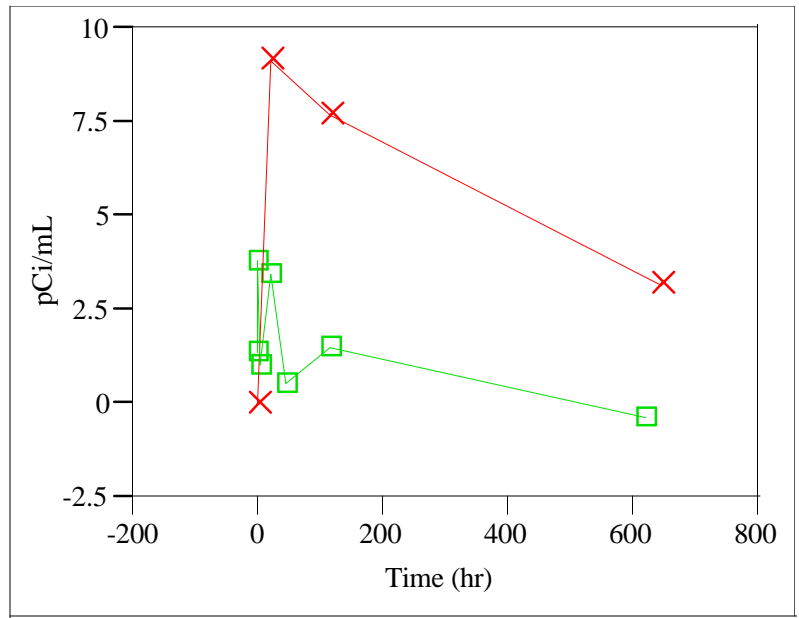

Sample ID=14

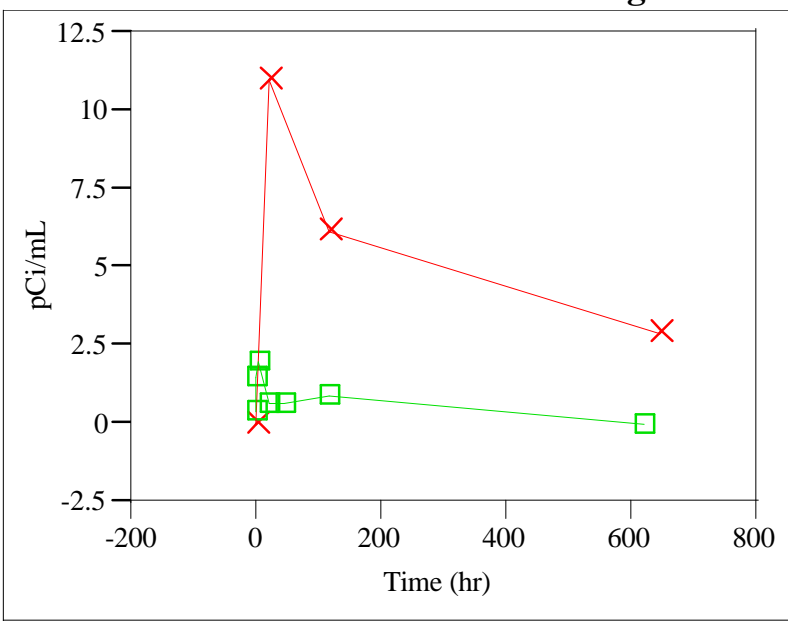

Sample ID=12B

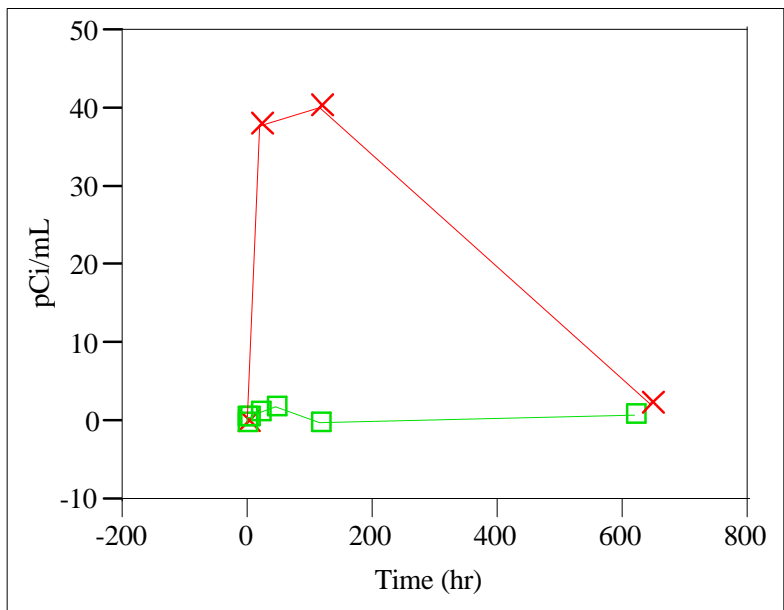

Sample ID=13B

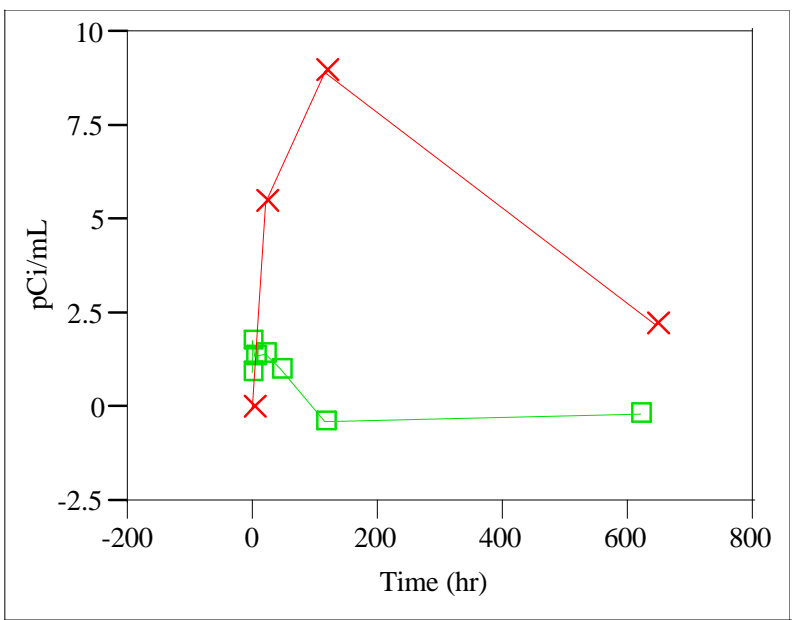

Sample ID=14B

$$
\text { - = monoliths } \mathrm{x}=\text { crushed }
$$

Figure 4-1. Plots of time dependence of leaching for monoliths and crushed samples. 
WSRC-TR-2004-00021, Rev. 0

January 12, 2004

Page 19 of 38

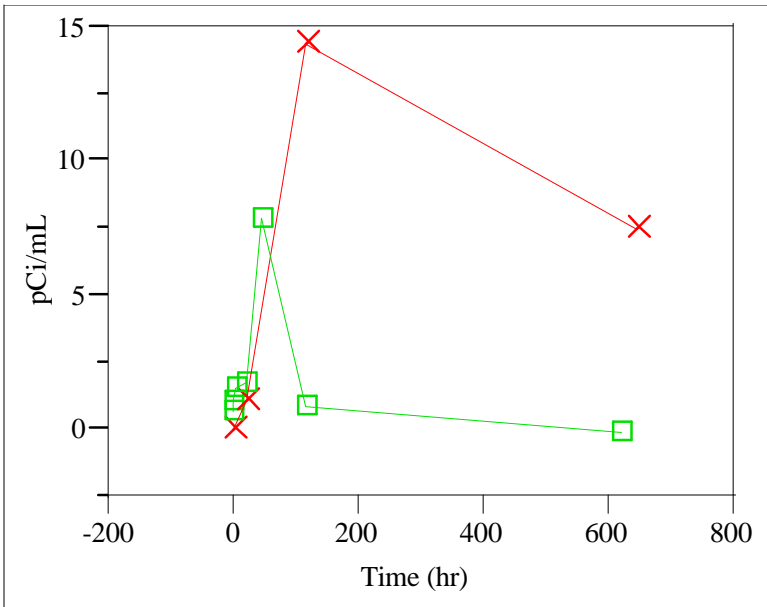

Sample ID=15

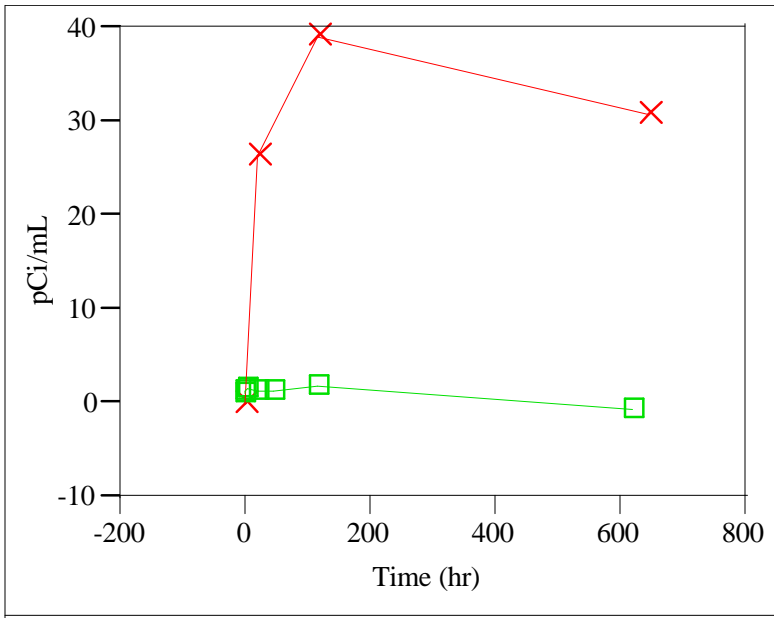

Sample ID=16

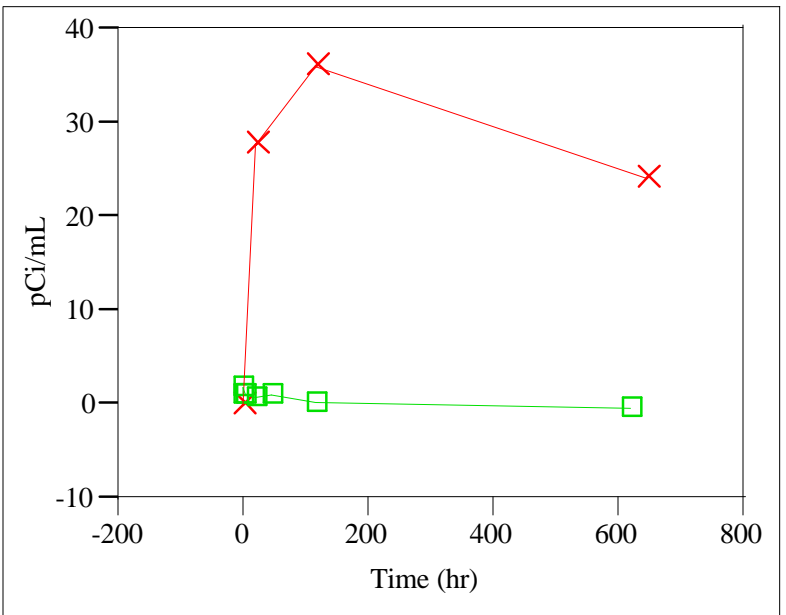

Sample ID=17

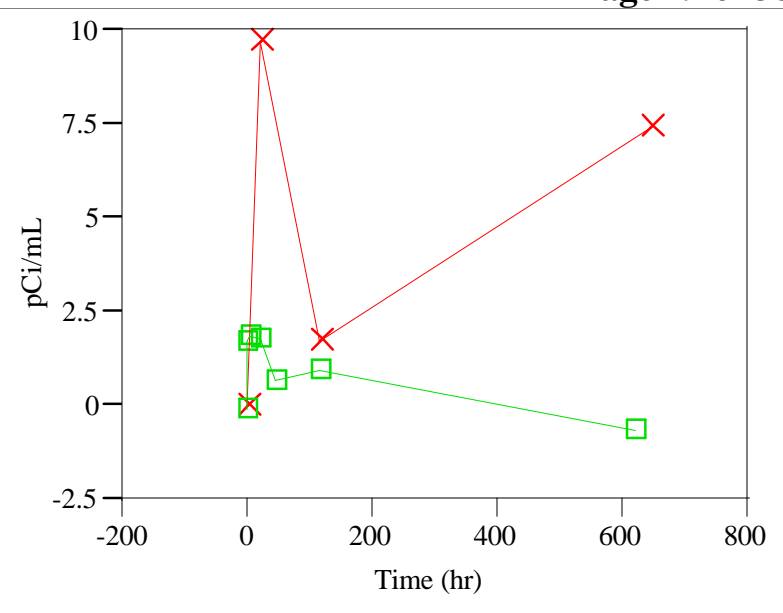

Sample ID $=15 B$

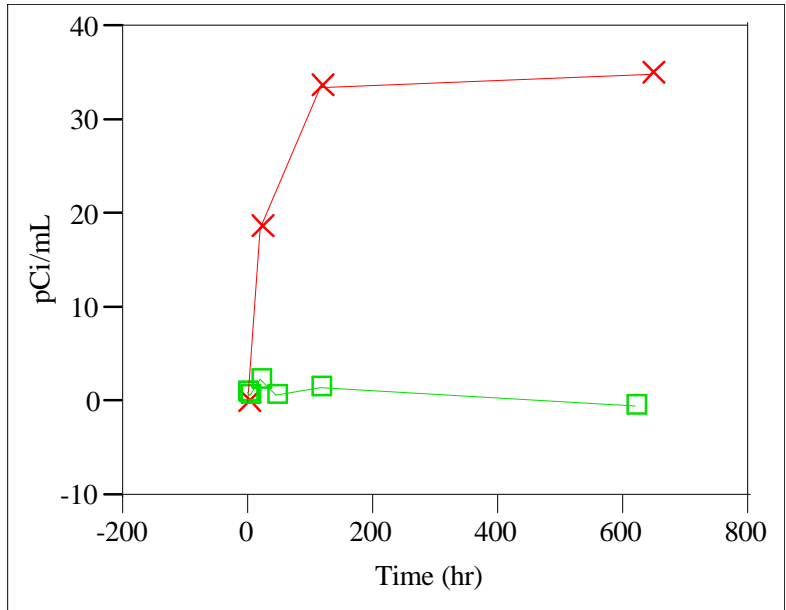

Sample ID=16B

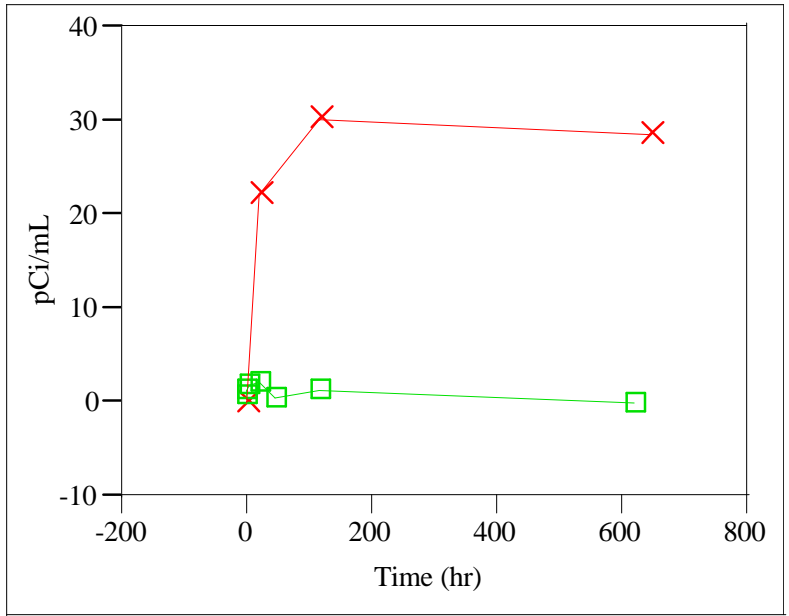

Sample ID=17B

$$
\text { - = monoliths } \mathrm{x}=\text { crushed }
$$

Figure 4-2. Plots of time dependence of leaching for monoliths and crushed samples. 


\subsection{Sorption/Desorption}

\subsubsection{Compatibility of Slag and Hydroxyapatite}

The sorption/desorption capacities of cured (aged) binders containing slag and/or hydroxyapatite were determined. Unspiked (no Tc-99) binder samples were crushed and contacted with one of three Tc-99 spiked liquids: DI water, Tank C-106 simulant, or Tank C-200 simulant. The following binders were used to evaluate the effects of slag and hydroxyapatite:

- Slag only (Binder 1)

- Hydroxyapatite only (Binder 7)

- Slag and Hydroxyapatite (Binder 4)

- No slag, no apatite (Binder 11).

\subsubsection{Sorption}

The sorption part of this test lasted five days. Samples were collected after 24, 72 and 120 hours of exposure. Spiked blanks, (no binder) were used to establish a baseline for the experiments. The initial concentrations in the blanks corresponded to about 1.9E-05 M Tc-99 but showed some scatter due to counting sensitivity and measurement errors from day to day and sample to sample. Concentrations of Tc-99 in the spiked liquids for binders 1, 4, 7, and 11 as a function of exposure time are provided in Table 4-7.

The Tc-99 concentrations in all the spiked liquids in contact with the crushed binders decreased relative to the concentrations in the blanks over the sorption phase of the experiment ( 5 days). Binder 11, without slag or HA sorbed some Tc-99 from the three contacting liquids.

\subsubsection{Desorption}

After termination of the 5-day sorption experiment, the same binder samples as used in the sorption experiment were contacted with unspiked DI water, simulated unspiked Tank C-106 supernate, or unspiked Tank C-200 average supernate. Tc-99 desorption was measured as a function of time. The first set of desorption samples were collected within one hour of completing the sorption testing on day 5. Tc-99 desorbed from these 4 samples during this phase of the test as indicated by the liquid (leachate) concentrations in Table 4-7.

Because of the uncertainty in the analytical measurements (indicated by day to day scatter in the blanks), the amount of Tc sorbed on to the 3-g samples was calculated at each time interval and then normalized with respect to the blanks for each series. The normalization process is describe below:

- Correct/normalize the spiked blank values measured for each of the three leachates at each leach interval with respect to the value measured for that spiked blank on day 0 .

- Apply the appropriate leach-interval/blank-normalization correction to each leachate. For example, all of the DIW concentrations including the day 1 blank for day 1 were multiplied by $2.55 \mathrm{E}+04 \mathrm{pCi} / \mathrm{ml}$ divided by $2.42 \mathrm{E} 04 \mathrm{pCi} / \mathrm{ml}$. 
WSRC-TR-2004-00021, Rev. 0

January 12, 2004

Page 21 of 38

The cumulative amounts of Tc-99 remaining on each of 3-gram crushed binder sample after 5 day of Tc-99 sorption followed by 20 days of desorption are shown in Table 4-8. Values were plotted in Figures 4-3 to 4-5 for comparison.

Table 4-7. Tc-99 concentrations in aqueous solutions (DI water, or tank heel supernates) in contact with crushed cured binders.

\begin{tabular}{|c|c|c|c|c|c|c|c|c|}
\hline \multirow[b]{3}{*}{ Sample ID } & \multirow{2}{*}{\multicolumn{4}{|c|}{$\begin{array}{l}\text { SORPTION EXPERIMENT } \\
\text { Tc-99 Concentrations in Leachates } \\
(\mathrm{pCi} / \mathrm{mL})\end{array}$}} & \multirow{2}{*}{\multicolumn{4}{|c|}{$\begin{array}{c}\text { DESORPTION EXPERIMENT } \\
\text { Tc-99 Concentrations in Leachates } \\
(\mathrm{pCi} / \mathrm{mL})\end{array}$}} \\
\hline & & & & & & & & \\
\hline & Day-0 & Day-1 & Day-3 & Day-5 & Day-5 & Day-6 & Day-10 & Day-25 \\
\hline DIBI & $2.55 \mathrm{E}+04$ & $2.42 \mathrm{E}+04$ & $2.43 \mathrm{E}+04$ & $1.99 \mathrm{E}+04$ & $6.79 E+00$ & 9.4 & $2.41 \mathrm{E}+01$ & $8.26 \mathrm{E}+00$ \\
\hline DI-1* & & $1.42 \mathrm{E}+04$ & $6.40 \mathrm{E}+03$ & $1.28 \mathrm{E}+04$ & 7.03E+00 & $1.40 \mathrm{E}+01$ & $3.84 \mathrm{E}+03$ & $5.12 \mathrm{E}+03$ \\
\hline DI-4*/* & & $1.70 \mathrm{E}+04$ & $9.44 \mathrm{E}+03$ & $1.35 \mathrm{E}+04$ & $0.00 \mathrm{E}+00$ & $1.54 \mathrm{E}+03$ & $3.31 \mathrm{E}+03$ & $5.82 \mathrm{E}+03$ \\
\hline DI-7* & & $1.91 \mathrm{E}+04$ & $1.94 \mathrm{E}+04$ & $1.99 \mathrm{E}+04$ & $3.16 \mathrm{E}+01$ & $3.53 \mathrm{E}+01$ & $1.44 \mathrm{E}+03$ & $1.50 \mathrm{E}+03$ \\
\hline DI-11* & & +04 & $2.13 \mathrm{E}+04$ & $1.96 \mathrm{E}+04$ & $2.01 \mathrm{E}+01$ & $1.02 \mathrm{E}+01$ & $7.94 \mathrm{E}+02$ & $7.05 \mathrm{E}+02$ \\
\hline C-1 & +04 & $2.12 \mathrm{E}+04$ & $2.22 \mathrm{E}+04$ & $6.47 \mathrm{E}+03$ & $7.21 \mathrm{E}+00$ & $2.36 \mathrm{E}+00$ & $7.76 \mathrm{E}+02$ & $4.98 \mathrm{E}+01$ \\
\hline C-1* & & +04 & 6.571 & +03 & $2.14 \mathrm{E}+00$ & +01 & $4.14 \mathrm{E}+03$ & $1.50 \mathrm{E}+03$ \\
\hline & & $8.88 \mathrm{E}+03$ & $8.08 \mathrm{E}+03$ & $1.30 \mathrm{E}+03$ & $4.16 \mathrm{E}+00$ & $1.26 \mathrm{E}+02$ & $4.82 \mathrm{E}+03$ & $2.92 \mathrm{E}+03$ \\
\hline C- & & +04 & 2.21 & +03 & $3 \mathrm{E}+01$ & +03 & +03 & +02 \\
\hline & & $2.18 \mathrm{E}+04$ & $2.18 \mathrm{E}+04$ & $8.41 \mathrm{E}+03$ & $4 \mathrm{E}+00$ & -01 & +03 & $4.26 \mathrm{E}+02$ \\
\hline & $2.46 \mathrm{E}+04$ & $2.28 \mathrm{E}+04$ & $2.26 \mathrm{E}+04$ & $1.80 \mathrm{E}+04$ & 7.74E+02 & $7.93 \mathrm{E}+02$ & 7.64E+02 & $8.67 \mathrm{E}+02$ \\
\hline 200-1* & & $1.95 \mathrm{E}+04$ & $1.51 \mathrm{E}$ & +03 & $2 \mathrm{E}+03$ & $2.81 \mathrm{E}+03$ & $3.91 \mathrm{E}+03$ & $5.01 \mathrm{E}+03$ \\
\hline 200-4* & & $2.00 \mathrm{E}+04$ & $1.70 \mathrm{E}+04$ & $1.75 \mathrm{E}+03$ & $9.49 \mathrm{E}+02$ & $3.94 \mathrm{E}+03$ & $5.07 \mathrm{E}+03$ & $5.82 \mathrm{E}+03$ \\
\hline & & $2.23 \mathrm{E}+04$ & $2.29 \mathrm{E}+04$ & $1.12 \mathrm{E}+04$ & $1.75 \mathrm{E}+03$ & $2.07 \mathrm{E}+03$ & $2.06 \mathrm{E}+03$ & $2.27 \mathrm{E}+03$ \\
\hline $200-11 *$ & & $2.24 \mathrm{E}+04$ & $2.31 \mathrm{E}+04$ & $9.56 \mathrm{E}+03$ & $1.51 \mathrm{E}+03$ & $2.03 \mathrm{E}+03$ & $2.06 \mathrm{E}+03$ & 2.39 \\
\hline
\end{tabular}

Timeline is in days after start of the sorption experiment.

*All of these samples used Kelco-Crete ${ }^{\circledR} / \mathrm{ADVA}^{\mathrm{TM}}$ Flow as the admixture and contained apatite and slag as follows: Binder 1 contained slag. Binder 4 contained slag and HA. Binder 7 contained HA. Binder 10 contained HA and sodium thiosulfate. Binder 11 contained no slag and no HA.

** Binder 4 is HRG 2 with Kelco-Crete ${ }^{\circledR} /$ ADVA $^{\mathrm{TM}}$ Flow. 
WSRC-TR-2004-00021, Rev. 0

January 12, 2004

Page 22 of 38

Table 4-8. Cumulative amount of Tc-99 sorbed on 3 grams of crushed binder samples as a function of time and exposure conditions.

\begin{tabular}{|l|c|c|c|c||c|c|c|}
\hline \multicolumn{5}{|c|}{ SORPTION EXPERIMENT } & \multicolumn{3}{c|}{ DESORPTION EXPERIMENT } \\
\hline \multicolumn{3}{|c|}{$\begin{array}{c}\text { Tc-99 Sorbed on 3-Grams of Binder } \\
\text { (pormal) } \\
\text { (Normalized with respect to Blank } \\
\text { (pCi) }\end{array}$} \\
\hline Sample ID & Day-0 & Day-1 & Day-3 & Day-5 & Day-6 & Day-10 & Day-25 \\
\hline DI-Blank & & & & & & \\
\hline DI-1* & $0.00 \mathrm{E}+00$ & $3.18 \mathrm{E}+05$ & $5.55 \mathrm{E}+05$ & $2.85 \mathrm{E}+05$ & $2.02 \mathrm{E}+02$ & $1.07 \mathrm{E}+05$ & $1.42 \mathrm{E}+05$ \\
\hline DI-4* & $0.00 \mathrm{E}+00$ & $2.30 \mathrm{E}+05$ & $4.60 \mathrm{E}+05$ & $2.53 \mathrm{E}+05$ & $4.47 \mathrm{E}+04$ & $9.42 \mathrm{E}+04$ & $1.62 \mathrm{E}+05$ \\
\hline DI-7* & $0.00 \mathrm{E}+00$ & $1.63 \mathrm{E}+05$ & $1.54 \mathrm{E}+05$ & $1.14 \mathrm{E}+04$ & $1.07 \mathrm{E}+02$ & $3.94 \mathrm{E}+04$ & $4.11 \mathrm{E}+04$ \\
\hline DI-11* & $0.00 \mathrm{E}+00$ & $1.29 \mathrm{E}+05$ & $9.52 \mathrm{E}+04$ & $1.90 \mathrm{E}+04$ & $-2.87 \mathrm{E}+02$ & $2.17 \mathrm{E}+04$ & $1.93 \mathrm{E}+04$ \\
\hline C-Blank & & & & & & & \\
\hline C-1* & $0.00 \mathrm{E}+00$ & $3.48 \mathrm{E}+05$ & $5.44 \mathrm{E}+05$ & $6.29 \mathrm{E}+05$ & $2.01 \mathrm{E}+03$ & $1.16 \mathrm{E}+05$ & $4.46 \mathrm{E}+04$ \\
\hline C-4* & $0.00 \mathrm{E}+00$ & $4.55 \mathrm{E}+05$ & $4.96 \mathrm{E}+05$ & $6.16 \mathrm{E}+05$ & $3.53 \mathrm{E}+03$ & $1.35 \mathrm{E}+05$ & $8.37 \mathrm{E}+04$ \\
\hline C-7* & $0.00 \mathrm{E}+00$ & $-1.40 \mathrm{E}+04$ & $1.70 \mathrm{E}+02$ & $-1.14 \mathrm{E}+05$ & $2.69 \mathrm{E}+05$ & $6.78 \mathrm{E}+04$ & $3.04 \mathrm{E}+04$ \\
\hline C-11* & $0.00 \mathrm{E}+00$ & $-2.14 \mathrm{E}+04$ & $1.02 \mathrm{E}+04$ & $-2.19 \mathrm{E}+05$ & $2.17 \mathrm{E}+03$ & $5.98 \mathrm{E}+04$ & $1.36 \mathrm{E}+04$ \\
\hline $\mathbf{2 0 0 - B l a n k}$ & & & & & & & \\
\hline $\mathbf{2 0 0 - 1 *}$ & $0.00 \mathrm{E}+00$ & $1.06 \mathrm{E}+05$ & $2.40 \mathrm{E}+05$ & $6.44 \mathrm{E}+05$ & $5.19 \mathrm{E}+04$ & $8.27 \mathrm{E}+04$ & $1.12 \mathrm{E}+05$ \\
\hline $\mathbf{2 0 0 - 4 *}$ & $0.00 \mathrm{E}+00$ & $9.00 \mathrm{E}+04$ & $1.79 \mathrm{E}+05$ & $6.31 \mathrm{E}+05$ & $8.67 \mathrm{E}+04$ & $1.18 \mathrm{E}+05$ & $1.39 \mathrm{E}+05$ \\
\hline $\mathbf{2 0 0 - 7 *}$ & $0.00 \mathrm{E}+00$ & $1.55 \mathrm{E}+04$ & $-9.95 \mathrm{E}+03$ & $2.59 \mathrm{E}+05$ & $9.28 \mathrm{E}+03$ & $9.00 \mathrm{E}+03$ & $1.47 \mathrm{E}+04$ \\
\hline $\mathbf{2 0 0 - 1 1 *}$ & $0.00 \mathrm{E}+00$ & $1.22 \mathrm{E}+04$ & $-1.64 \mathrm{E}+04$ & $3.22 \mathrm{E}+05$ & $1.51 \mathrm{E}+04$ & $1.59 \mathrm{E}+04$ & $-3.32 \mathrm{E}+04$ \\
\hline
\end{tabular}

*All samples contained Kelco-Crete ${ }^{\circledR} / \mathrm{ADVA}^{\mathrm{T}}$ Flow as the admixture and contained hydroxyapatite and slag as follows: Binder 1 contained slag. Binder 4 contained slag and HA. Binder 7 contained HA.

Binder 11 contained no slag and no HA. 
WSRC-TR-2004-00021, Rev. 0

January 12, 2004

Page 23 of 38

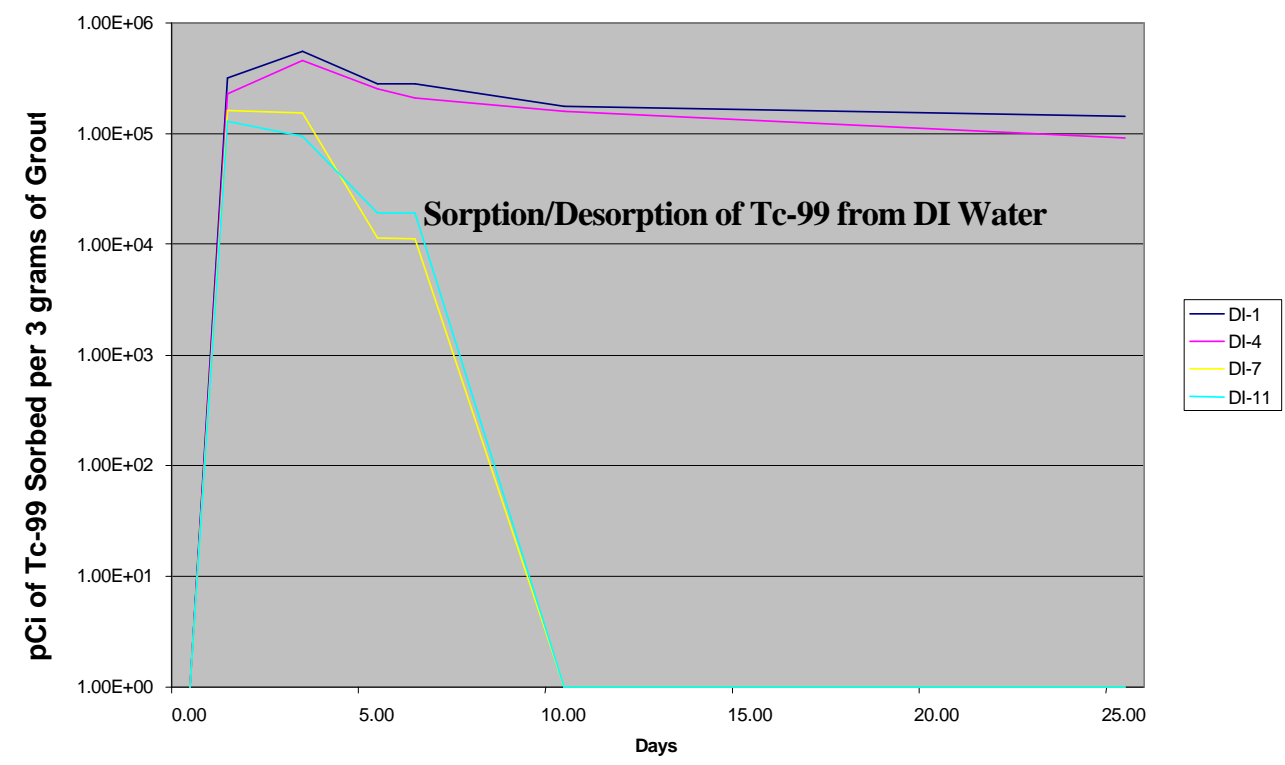

Figure 4-3. Tc-99 retained on 3 grams of samples w/wo slag and HA exposed to DI water.

(Samples were contacted with DI water containing Tc-99 for first 5 days then rinsed and leached with DI water.)

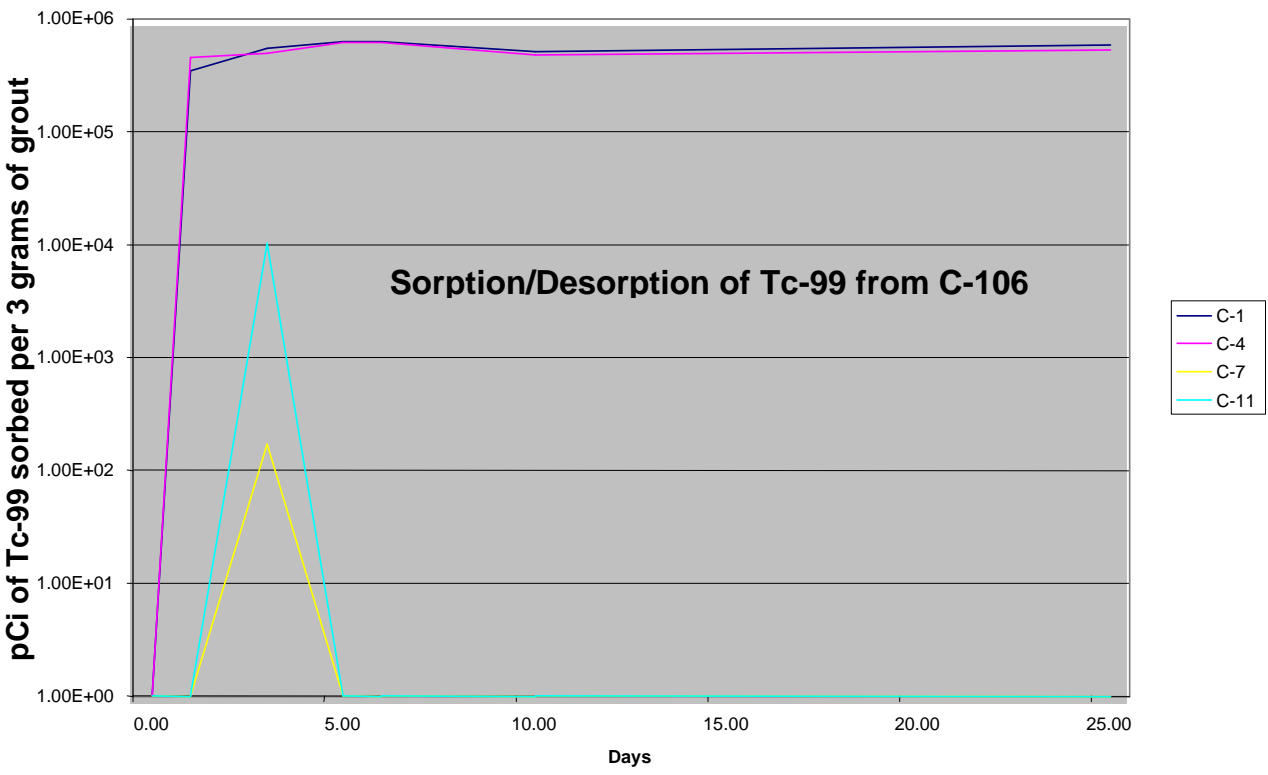

Figure 4-4. Tc-99 retained on 3 grams of sample w/wo slag and HA in Tank C-106 simulant.

(Samples were contacted with simulant containing Tc-99 for first 5 days then rinsed and leached with Tc-99 free simulant.) 
WSRC-TR-2004-00021, Rev. 0

January 12, 2004

Page 24 of 38

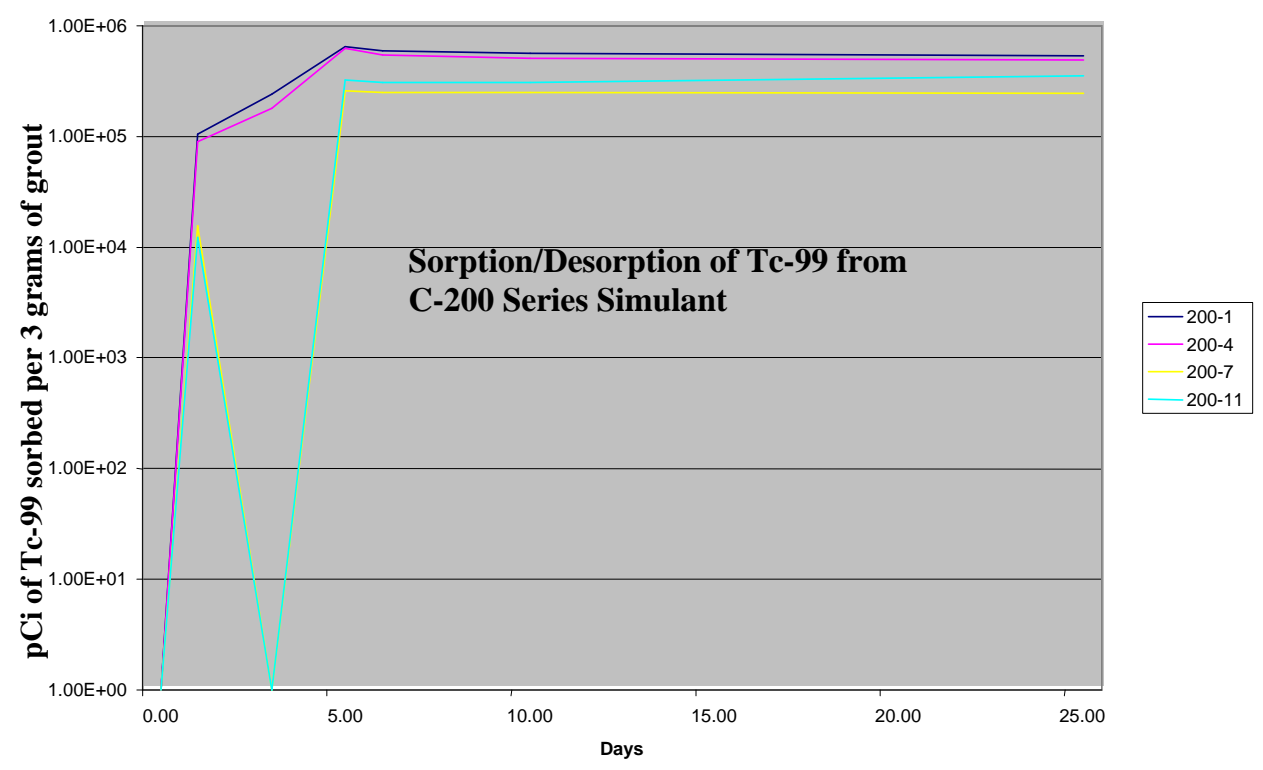

Figure 4-5. Tc-99 retained on 3 grams of sample w/wo slag and HA in Tank C-200 series simulant.

(Samples were contacted with simulant containing Tc-99 for first 5 days then rinsed and leached with Tc-99 free simulant.)

\subsubsection{Effect of Processing Admixtures on Stabilization}

The effect of three different grout-processing admixtures on the Tc-99 sorption capacity of hydroxyapatite was also evaluated.

Hydroxyapatite was added to a mixture of cement, slag and fly ash that corresponds to the cementitious ingredients and proportions in Binder HRG 2. The following binders were prepared with equal amounts of slag and fly ash and used to evaluate the effects of grout admixtures on binders containing both slag and hydroxyapatite:

- Kelco-Crete ${ }^{\circledR} /$ ADVA $^{\mathrm{m}} \mathrm{Flow}$ (Binder 4)

- Methocel (Binder 5)

- MaxFlow (Binder 6).

After curing, these unspiked (no Tc-99) binder samples were crushed and the first exposed to Tc99 containing liquid (DI water, Tank C-106 simulant, or Tank C-200 simulant) for 5 days (sorption test) and then leached in the leachate (same composition as used during the sorption test) without Tc-99.

\subsubsection{Sorption}

The sorption part of this test lasted five days. Samples were collected after 24, 72 and 120 hours of exposure. Spiked Blanks, (no binder) were used to establish a baseline for the experiments. The initial concentrations in the blanks correspond to about 1.9E-05 M Tc-99 but showed some scatter due to counting sensitivity and measurement errors from day to day and sample to sample. 
Concentrations of Tc-99 in all of the spiked liquids as a function of exposure time are summarized in Table 4-9. The Tc-99 concentrations in all the spiked liquids in contact with the crushed binders decreased relative to the concentrations in the blanks over the sorption phase of the experiment.

\subsubsection{Desorption}

After the 5-day sorption experiment, Tc-99 desorption was measured for these same binder samples by leaching them in DI water or one of the simulated tank heel supernate without Tc-99. The spiked Blanks, (no binder) were used to establish a baseline for the experiments. Results are tabulated as a function of contact time in Table 4-9.

Because of the uncertainty in the analytical measurements (day to day scatter in the blanks), the amount of Tc sorbed on to each 3-g sample was calculated for every time interval and then normalized with respect to the blanks for each series and day as described in Section 4.4.1.2. See table 4-10. Results are plotted in Figures 4-6 to 4-8 as a function of time to identify trends.

Table 4-9. Tc-99 concentrations in aqueous solutions in contact with crushed cured binders.

\begin{tabular}{|c|c|c|c|c|c|c|c|c|}
\hline \multirow[b]{3}{*}{ Sample ID } & \multirow{2}{*}{\multicolumn{4}{|c|}{$\begin{array}{l}\text { SORPTION EXPERIMENT } \\
\text { c-99 Concentrations in Leachates } \\
(\mathrm{pCi} / \mathrm{mL})\end{array}$}} & \multirow{2}{*}{\multicolumn{4}{|c|}{$\begin{array}{l}\text { DESORPTION EXPERIMENT } \\
\text { Tc-99 Concentrations in Leachates } \\
(\mathrm{pCi} / \mathrm{mL})\end{array}$}} \\
\hline & & & & & & & & \\
\hline & Day-0 & Day-1 & Day-3 & Day-5 & Day-5 & Day-6 & Day-10 & Day-25 \\
\hline DIBlank & $2.55 \mathrm{E}+04$ & $2.42 \mathrm{E}+04$ & $2.43 \mathrm{E}+04$ & $1.99 \mathrm{E}+04$ & $6.79 \mathrm{E}+00$ & 9.44E-01 & $2.41 \mathrm{E}+01$ & $8.26 \mathrm{E}+00$ \\
\hline DI-4** & & $1.70 \mathrm{E}+04$ & $9.44 \mathrm{E}+03$ & $1.35 \mathrm{E}+04$ & $0.00 \mathrm{E}+00$ & $1.54 \mathrm{E}+03$ & $3.31 \mathrm{E}+03$ & $5.82 \mathrm{E}+03$ \\
\hline DI-5** & & $2.04 \mathrm{E}+04$ & $1.21 \mathrm{E}+04$ & $1.67 \mathrm{E}+04$ & $2.06 \mathrm{E}+00$ & $3.05 \mathrm{E}+02$ & $6.53 \mathrm{E}+02$ & $4.88 \mathrm{E}+03$ \\
\hline DI-6** & & $2.05 \mathrm{E}+04$ & $1.57 \mathrm{E}+04$ & $1.95 \mathrm{E}+04$ & $1.80 \mathrm{E}+00$ & $7.77 \mathrm{E}+02$ & $9.96 \mathrm{E}+02$ & $4.46 \mathrm{E}+03$ \\
\hline C-Blank & $2.61 \mathrm{E}+04$ & $2.12 \mathrm{E}+04$ & $2.22 \mathrm{E}+04$ & $6.47 \mathrm{E}+03$ & $7.21 \mathrm{E}+00$ & $2.36 \mathrm{E}+00$ & $7.76 \mathrm{E}+02$ & $4.98 \mathrm{E}+01$ \\
\hline C-4** & & $8.88 \mathrm{E}+03$ & $8.08 \mathrm{E}+03$ & $1.30 \mathrm{E}+03$ & $4.16 \mathrm{E}+00$ & $1.26 \mathrm{E}+02$ & $4.82 \mathrm{E}+03$ & $2.92 \mathrm{E}+03$ \\
\hline $\mathrm{C}-5^{* *}$ & & $1.65 \mathrm{E}+04$ & $8.54 \mathrm{E}+03$ & $1.19 \mathrm{E}+03$ & $1.97 \mathrm{E}+00$ & $4.27 \mathrm{E}+02$ & $4.15 \mathrm{E}+03$ & $3.53 \mathrm{E}+03$ \\
\hline C-6** & & $1.65 \mathrm{E}+04$ & $8.88 \mathrm{E}+03$ & $1.55 \mathrm{E}+03$ & $2.46 \mathrm{E}+00$ & $7.87 \mathrm{E}+02$ & $2.16 \mathrm{E}+03$ & $5.07 \mathrm{E}+03$ \\
\hline 200Blank & $2.46 \mathrm{E}+04$ & $2.28 \mathrm{E}+04$ & $2.26 \mathrm{E}+04$ & $1.80 \mathrm{E}+04$ & $7.74 \mathrm{E}+02$ & $7.93 \mathrm{E}+02$ & $7.64 \mathrm{E}+02$ & $8.67 \mathrm{E}+02$ \\
\hline $200-4^{* *}$ & & $2.00 \mathrm{E}+04$ & $1.70 \mathrm{E}+04$ & $1.75 \mathrm{E}+03$ & $9.49 \mathrm{E}+02$ & $3.94 \mathrm{E}+03$ & $5.07 \mathrm{E}+03$ & $5.82 \mathrm{E}+03$ \\
\hline $200-5 * *$ & & $2.20 \mathrm{E}+04$ & $1.86 \mathrm{E}+04$ & $3.31 \mathrm{E}+03$ & $1.34 \mathrm{E}+03$ & $3.46 \mathrm{E}+03$ & $3.84 \mathrm{E}+03$ & $4.44 \mathrm{E}+03$ \\
\hline $200-6^{* * *}$ & & $2.19 \mathrm{E}+04$ & $2.22 \mathrm{E}+04$ & $4.58 \mathrm{E}+03$ & $1.47 \mathrm{E}+03$ & $2.03 \mathrm{E}+03$ & $2.15 \mathrm{E}+03$ & $2.46 \mathrm{E}+03$ \\
\hline
\end{tabular}

Timeline is in days after start of the sorption experiment.

** Binder 4 is HRG 2 with Kelco-Crete ${ }^{\circledR} /$ ADVA $^{\mathrm{TM}}$ Flow. Binder 5 is HRG 2 with Methocel. Binder 6 is HRG 2 with MaxFlow. 
WSRC-TR-2004-00021, Rev. 0

January 12, 2004

Page 26 of 38

Table 4-10. Cumulative amount of Tc-99 sorbed on 3 grams of crushed binder samples as a function of time and exposure conditions.

\begin{tabular}{|c|c|c|c|c|c|c|c|}
\hline \multirow[b]{3}{*}{ Sample ID } & \multicolumn{4}{|c|}{ SORPTION EXPERIMENT } & \multicolumn{3}{|c|}{ DESORPTION EXPERIMENT } \\
\hline & \multicolumn{4}{|c|}{$\begin{array}{l}\text { Tc-99 Sorbed on 3-Grams of Binder } \\
\text { (Normalized with respect to Blank } \\
\text { concentrations) } \quad \text { (pCi) }\end{array}$} & \multicolumn{3}{|c|}{$\begin{array}{l}\text { Tc-99 Sorbed on 3-Grams of Binder } \\
\text { (Normalized with respect to Blank } \\
\text { concentrations) } \quad \text { (pCi) }\end{array}$} \\
\hline & Day-0 & Day-1 & Day-3 & Day-5 & Day-6 & Day-10 & Day-25 \\
\hline \multicolumn{8}{|l|}{ DI-Blank } \\
\hline DI-4** & $0.00 \mathrm{E}+00$ & $2.30 \mathrm{E}+05$ & $4.60 \mathrm{E}+05$ & $2.53 \mathrm{E}+05$ & 4.47E+04 & $9.42 \mathrm{E}+04$ & $1.62 \mathrm{E}+05$ \\
\hline DI-5** & $0.00 \mathrm{E}+00$ & $1.22 \mathrm{E}+05$ & $3.75 \mathrm{E}+05$ & $1.32 \mathrm{E}+05$ & $8.79 \mathrm{E}+03$ & $1.85 \mathrm{E}+04$ & $1.33 \mathrm{E}+05$ \\
\hline DI-6** & $0.00 \mathrm{E}+00$ & $1.19 \mathrm{E}+05$ & $2.65 \mathrm{E}+05$ & $2.81 \mathrm{E}+04$ & $2.25 \mathrm{E}+04$ & $2.86 \mathrm{E}+04$ & $1.22 \mathrm{E}+05$ \\
\hline \multicolumn{8}{|l|}{ C-Blank } \\
\hline $\mathrm{C}-4 * *$ & $0.00 \mathrm{E}+00$ & $4.55 \mathrm{E}+05$ & $4.96 \mathrm{E}+05$ & $6.16 \mathrm{E}+05$ & $3.53 \mathrm{E}+03$ & $1.35 \mathrm{E}+05$ & $8.37 \mathrm{E}+04$ \\
\hline $\mathrm{C}-5^{* *}$ & $0.00 \mathrm{E}+00$ & $1.74 \mathrm{E}+05$ & $4.70 \mathrm{E}+05$ & $6.18 \mathrm{E}+05$ & $1.23 \mathrm{E}+04$ & $1.17 \mathrm{E}+05$ & $9.98 \mathrm{E}+04$ \\
\hline C-6** & $0.00 \mathrm{E}+00$ & $1.74 \mathrm{E}+05$ & $4.59 \mathrm{E}+05$ & $5.77 \mathrm{E}+05$ & $2.28 \mathrm{E}+04$ & $6.12 \mathrm{E}+04$ & $1.40 \mathrm{E}+05$ \\
\hline \multicolumn{8}{|l|}{ 200-Blank } \\
\hline $200-4 * *$ & $0.00 \mathrm{E}+00$ & $9.00 \mathrm{E}+04$ & $1.79 \mathrm{E}+05$ & $6.31 \mathrm{E}+05$ & $8.67 \mathrm{E}+04$ & $1.18 \mathrm{E}+05$ & $1.39 \mathrm{E}+05$ \\
\hline $200-5 * *$ & $0.00 \mathrm{E}+00$ & $2.52 \mathrm{E}+04$ & $1.26 \mathrm{E}+05$ & $5.67 \mathrm{E}+05$ & $6.15 \mathrm{E}+04$ & $7.21 \mathrm{E}+04$ & $8.83 \mathrm{E}+04$ \\
\hline $200-6^{* *}$ & $0.00 \mathrm{E}+00$ & $2.84 \mathrm{E}+04$ & $1.26 \mathrm{E}+04$ & $5.14 \mathrm{E}+05$ & $1.62 \mathrm{E}+04$ & $1.96 \mathrm{E}+04$ & $2.80 \mathrm{E}+04$ \\
\hline
\end{tabular}

Timeline is in days after start of the sorption experiment.

** Binder 4 is HRG 2 with Kelco-Crete ${ }^{\circledR} /$ ADVA $^{\mathrm{TM}}$ Flow. Binder 5 is HRG 2 with Methocel. Binder 6 is HRG 2 with MaxFlow. 
WSRC-TR-2004-00021, Rev. 0

January 12, 2004

Page 27 of 38

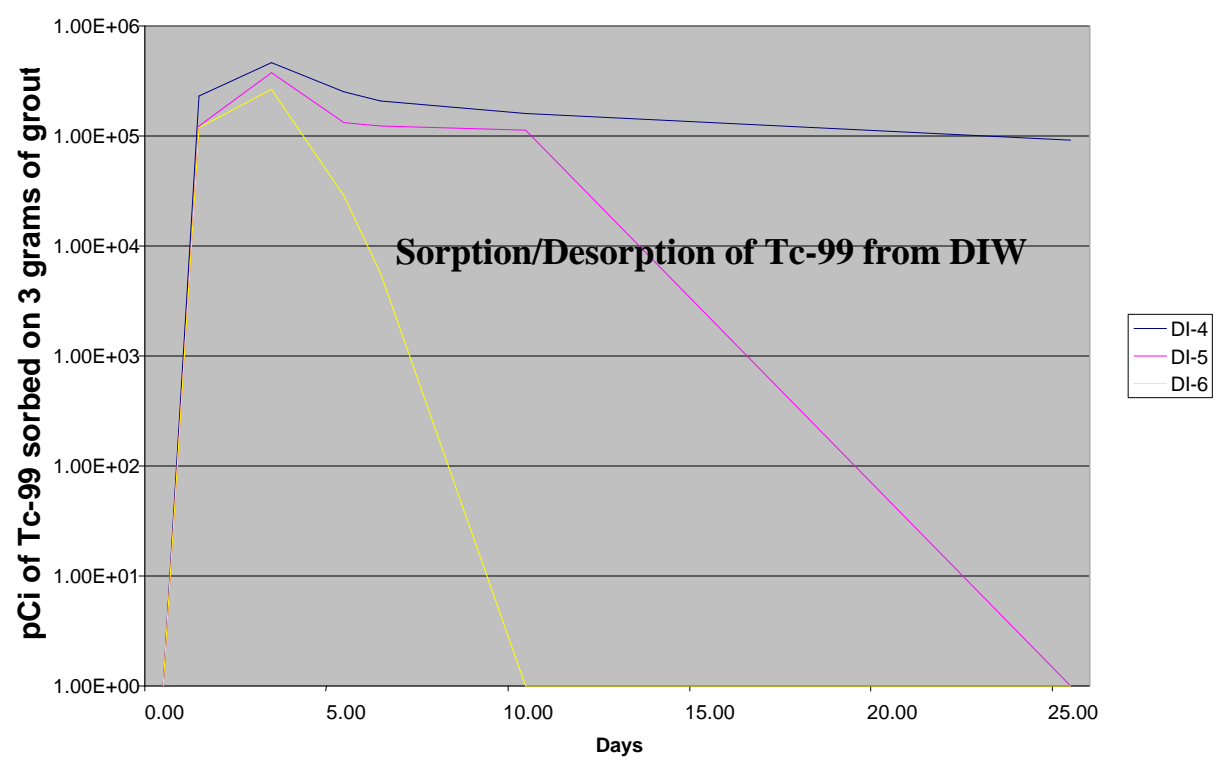

Figure 4-6. Tc-99 retained on 3 grams of samples of HRG 2 with 3 different processing admixtures exposed to DI water.

(Samples were contacted with DI water containing Tc-99 for first 5 days then rinsed and leached with DI water.)

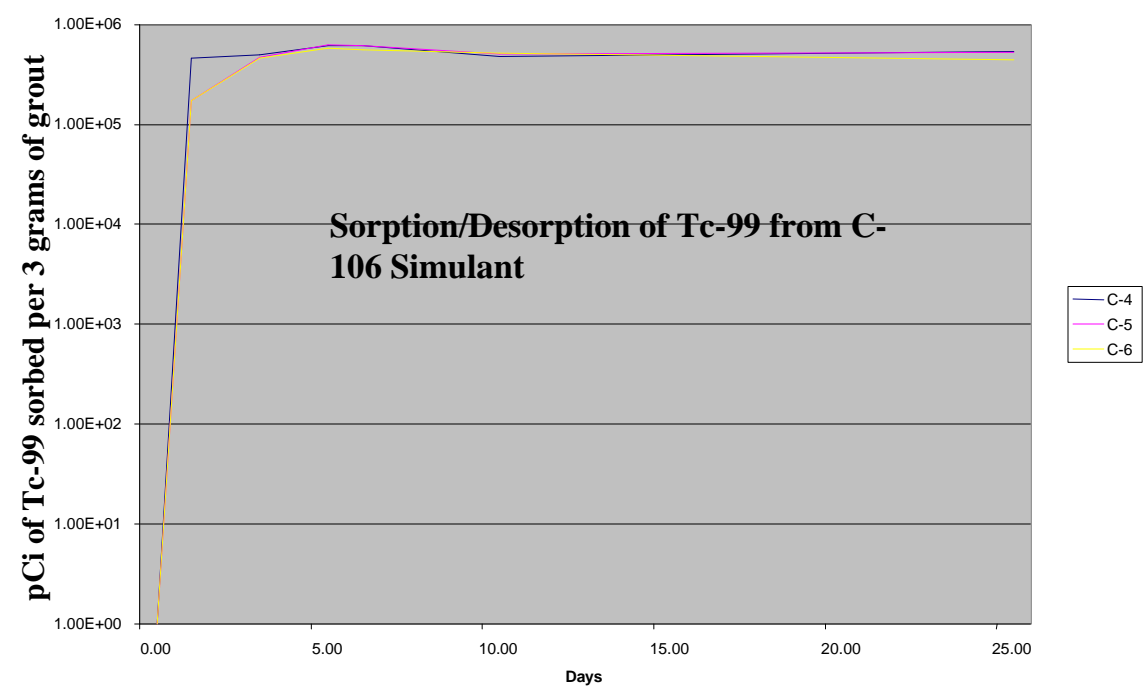

Figure 4-7. Tc-99 retained on 3 gram samples of HRG 2 with 3 different processing admixtures exposed to $\mathrm{C}-106$ simulant.

(Samples were contacted with simulant containing Tc-99 for the first 5 days then rinsed and leached with Tc-99-free C-106 simulant.) 


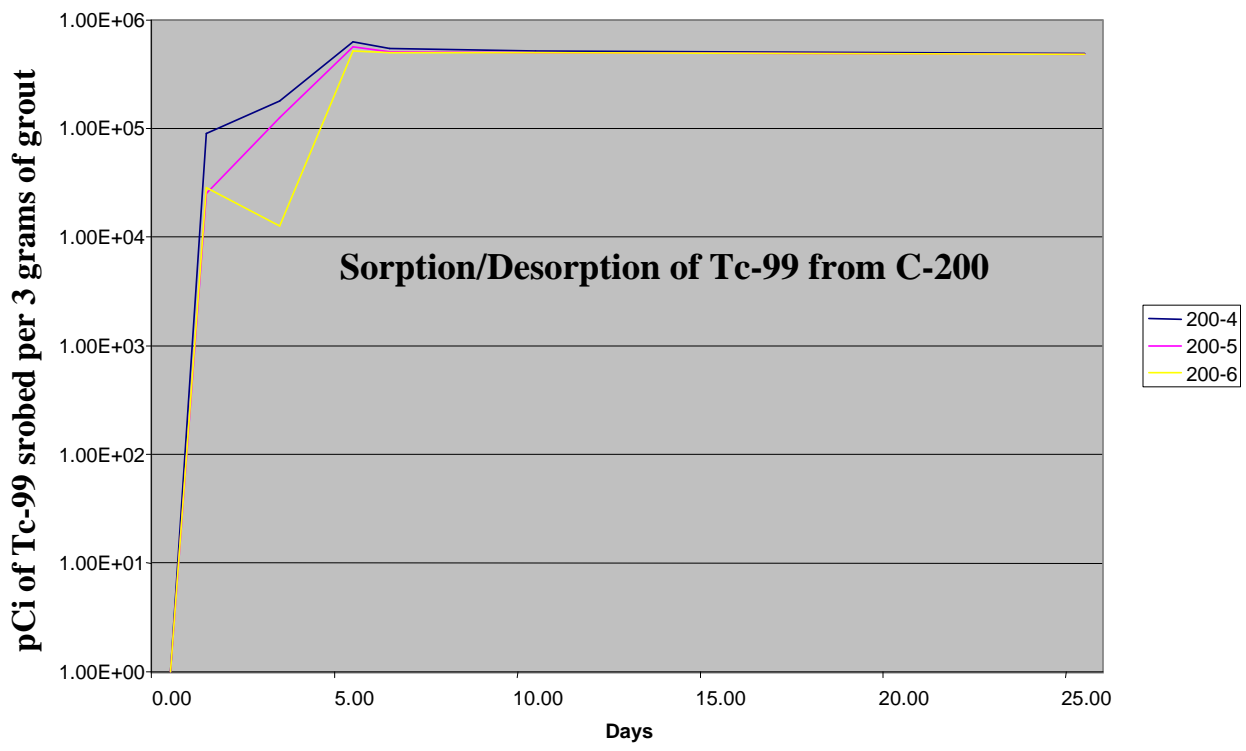

Figure 4-8. Tc-99 retained on 3-gram samples of HRG 2 with 3 different processing admixtures exposed to $\mathrm{C}-200$ series simulant.

(Samples were contacted with simulant containing Tc-99 for first 5 days then rinsed and leached with Tc-99 free C-200 simulant.)

\subsubsection{Effect of Sodium Thiosulfate on Hydroxyapatite}

The effect of adding sodium thiosulfate, a fast acting soluble chemical reductant, to the mixing solutions was evaluated for a binder containing hydroxyapatite (Binder 10). Tc-99 concentrations in the sorption and desorption phases of the experiment are listed in Table 4-11.

Table 4-11. Tc-99 concentrations in aqueous solutions (DI water, or tank heel supernates) in contact with crushed cured binders containing $\mathrm{HA}$ and sodium thiosulfate.

\begin{tabular}{|l|c|c|c|c||c|c|c|c|}
\hline & \multicolumn{3}{|c||}{$\begin{array}{c}\text { SORPTION EXPERIMENT } \\
\text { (pCi/mL) }\end{array}$} & \multicolumn{3}{c|}{ DESORPTION EXPERIMENT } \\
\hline & \multicolumn{3}{|c|}{ Tc-99 Concentrations in Leachates } & \multicolumn{3}{c|}{$\begin{array}{c}\text { Tc-99 Concentrations in Leachates } \\
\text { (pCi/mL) }\end{array}$} \\
\hline Sample ID & Day-0 & Day-1 & Day-3 & Day-5 & Day-5 & Day-6 & Day-10 & Day-25 \\
\hline DIBlank & $2.55 \mathrm{E}+04$ & $2.42 \mathrm{E}+04$ & $2.43 \mathrm{E}+04$ & $1.99 \mathrm{E}+04$ & $6.79 \mathrm{E}+00$ & $9.44 \mathrm{E}-01$ & $2.41 \mathrm{E}+01$ & $8.26 \mathrm{E}+00$ \\
\hline DI-10* & & $2.07 \mathrm{E}+04$ & $2.09 \mathrm{E}+04$ & $1.95 \mathrm{E}+04$ & $1.84 \mathrm{E}+01$ & $1.32 \mathrm{E}+02$ & $6.38 \mathrm{E}+02$ & $8.20 \mathrm{E}+02$ \\
\hline C-Blank & $2.61 \mathrm{E}+04$ & $2.12 \mathrm{E}+04$ & $2.22 \mathrm{E}+04$ & $6.47 \mathrm{E}+03$ & $7.21 \mathrm{E}+00$ & $2.36 \mathrm{E}+00$ & $7.76 \mathrm{E}+02$ & $4.98 \mathrm{E}+01$ \\
\hline C-10* & & $2.18 \mathrm{E}+04$ & $2.19 \mathrm{E}+04$ & $6.70 \mathrm{E}+03$ & $2.19 \mathrm{E}+01$ & $8.60 \mathrm{E}+01$ & $2.01 \mathrm{E}+03$ & $4.85 \mathrm{E}+02$ \\
\hline $\mathbf{2 0 0 B l a n k}$ & $2.46 \mathrm{E}+04$ & $2.28 \mathrm{E}+04$ & $2.26 \mathrm{E}+04$ & $1.80 \mathrm{E}+04$ & $7.74 \mathrm{E}+02$ & $7.93 \mathrm{E}+02$ & $7.64 \mathrm{E}+02$ & $8.67 \mathrm{E}+02$ \\
\hline $\mathbf{2 0 0 - 1 0 *}$ & & $2.21 \mathrm{E}+04$ & $2.30 \mathrm{E}+04$ & $1.05 \mathrm{E}+04$ & $1.49 \mathrm{E}+03$ & $2.07 \mathrm{E}+03$ & $1.98 \mathrm{E}+03$ & $2.44 \mathrm{E}+03$ \\
\hline
\end{tabular}

Timeline is in days after start of the sorption experiment. 
The cumulative amounts of Tc-99 sorbed on the 3 grams of the crushed binder samples are listed in Table 4-12 and plotted in Figure 4-9. The sodium thiosulfate had little effect on Tc-99 sorption/desorption results. The HA was still effective even when a chemical reductant was added to the binder composition.

Table 4-12. Cumulative amount of Tc-99 sorbed on 3 grams of crushed binder samples containing $\mathrm{HA}$ and sodium thiosulfate as a function of time and exposure conditions.

\begin{tabular}{|c|c|c|c|c|c|c|c|}
\hline & \multicolumn{4}{|c|}{ SORPTION EXPERIMENT } & \multicolumn{3}{|c|}{ DESORPTION EXPERIMENT } \\
\hline & \multicolumn{4}{|c|}{$\begin{array}{l}\text { Tc-99 Sorbed on 3-Grams of Binder } \\
\text { (Normalized with respect to Blank } \\
\text { concentrations) } \quad \text { (pCi) }\end{array}$} & \multicolumn{3}{|c|}{$\begin{array}{l}\text { Tc-99 Sorbed on 3-Grams of Binder } \\
\text { (Normalized with respect to Blank } \\
\text { concentrations) } \quad \text { (pCi) }\end{array}$} \\
\hline Sample ID & Day-0 & Day-1 & Day-3 & Day-5 & Day-6 & Day-10 & Day-25 \\
\hline \multicolumn{8}{|l|}{ DI-Blank } \\
\hline DI-10* & $0.00 \mathrm{E}+00$ & $1.13 \mathrm{E}+05$ & $1.07 \mathrm{E}+05$ & $2.24 \mathrm{E}+04$ & $3.29 \mathrm{E}+03$ & $1.75 \mathrm{E}+04$ & $2.24 \mathrm{E}+04$ \\
\hline \multicolumn{8}{|l|}{ C-Blank } \\
\hline C-10* & $0.00 \mathrm{E}+00$ & $-2.14 \mathrm{E}+04$ & $6.77 \mathrm{E}+03$ & $-2.57 \mathrm{E}+04$ & $1.86 \mathrm{E}+03$ & $5.57 \mathrm{E}+04$ & $1.46 \mathrm{E}+04$ \\
\hline \multicolumn{8}{|l|}{ 200-Blank } \\
\hline 200-10* & $0.00 \mathrm{E}+00$ & $2.20 \mathrm{E}+04$ & $-1.29 \mathrm{E}+04$ & $2.86 \mathrm{E}+05$ & $1.68 \mathrm{E}+04$ & $1.43 \mathrm{E}+04$ & $2.67 \mathrm{E}+04$ \\
\hline
\end{tabular}

Timeline is in days after start of the sorption experiment.

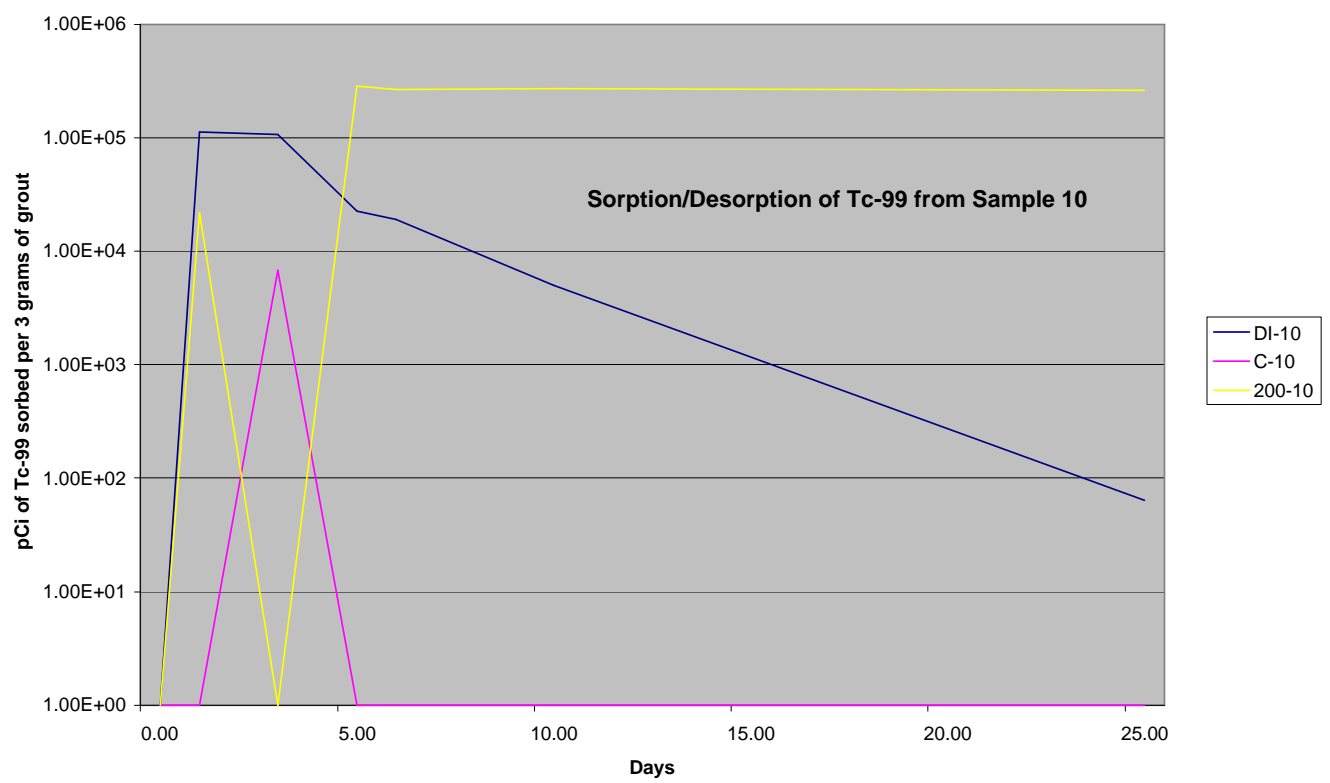

Figure 4-9. Tc-99 retained on 3-gram samples of grout containing HA and sodium thiosulfate after exposure to 3 different leachates. 
WSRC-TR-2004-00021, Rev. 0

January 12, 2004

Page 30 of 38

\subsubsection{Relative Sorption Capacity of Reducing and Non-Reducing Binders}

An overall comparison of the Tc-99 sorption capacities of six reducing binders (Binders 1, 4, 5, $6,7,10)$ and a binder that is not reducing (Binder 11) is presented in Table 4-13. The comparison was made on the basis of the amount of Tc-99 sorbed on the 3-gram crushed samples after 1, 3, and 5 days exposure divided by the total amount of Tc-99 present in the initial solutions. The percentages shown in Table 4-13 were calculated from data corrected for sampling losses (1-mL per sampling).

Table 4-13. Percent Tc-99 sorbed on the 3 grams samples after 1, 3, and 5 days exposure.

\begin{tabular}{|c|c|c|c|}
\hline & \multicolumn{2}{|c|}{ Percent Tc-99 Sorbed from aqueous solution } & \multirow[b]{2}{*}{5 Days } \\
\hline Exposure time & 1 Day & 3 Days & \\
\hline \multicolumn{4}{|l|}{ Sample No. } \\
\hline DI-1* & 42 & 73 & 37 \\
\hline DI-4*/** & 30 & 60 & 33 \\
\hline DI-5*** & 16 & 49 & 17 \\
\hline DI-6** & 16 & 35 & 4 \\
\hline DI-7* & 21 & 20 & 1 \\
\hline DI-10* & 15 & 14 & 3 \\
\hline DI-11* & 17 & 12 & 2 \\
\hline C-1* & 44 & 69 & 80 \\
\hline $\mathrm{C}-4 * / * *$ & 58 & 63 & 79 \\
\hline $\mathrm{C}-5 * *$ & 22 & 60 & 79 \\
\hline C-6** & 22 & 59 & 74 \\
\hline $\mathrm{C}-7^{*}$ & 0 & 0 & 0 \\
\hline C-10* & 0 & 1 & 0 \\
\hline C-11* & 0 & 1 & 0 \\
\hline 200-1* & 14 & 32 & 87 \\
\hline $200-4 * / * *$ & 12 & 24 & 85 \\
\hline $200-5 * *$ & 3 & 17 & 77 \\
\hline $200-6 * *$ & 4 & 2 & 70 \\
\hline $200-7 *$ & 2 & 0 & 35 \\
\hline $200-10 *$ & 3 & 0 & 39 \\
\hline $200-11 *$ & 2 & 0 & 44 \\
\hline
\end{tabular}

*All of these samples use Kelco-Crete ${ }^{\circledR} / \mathrm{ADVA}^{\mathrm{TM}}$ Flow as the admixture and contain apatite and slag as follows: Binder 1 contains slag. Binder 4 contains slag and HA. Binder 7 contains HA. Binder 10 contains HA and sodium thiosulfate. Binder 11 contains no slag and no HA.

** Binder 4 is HRG 2 with Kelco-Crete ${ }^{\circledR} /$ ADVA $^{\mathrm{TM}}$ Flow. Binder 5 is HRG 2 with Methocel. Binder 6 is HRG 2 with MaxFlow. 


\subsection{DISCUSSION}

\subsection{MONOLITH LEACHING}

Effective diffusivities and Leach Indices (L) for Tc-99, the only contaminant of concern identified by CH2M HILL, were calculated from the leaching data obtained from the abbreviated ANSI/ANS 16.1 protocol. Monolithic binder samples were leached in three different leaching fluids to determine the effect of leachate chemistry on Tc-99 stabilization. In addition to a reference case using deionized water, the leaching fluids were selected to simulate to infiltrating water in contact with tank fill grout, an oxalate-caustic tank supernate (Tank C-106), and a concentrated sodium salt supernate-aluminum hydroxide heel (average C-200 series).

Monolith leaching was also intended to provide information on the performance of intact (nondegraded) tank fill grout with respect to Tc-99 stabilization. The monoliths leached in this study consisted of the cementitious binder ingredients plus selected admixtures (water reducers and viscosifiers) that were previously evaluated for use as grout processing aids.

The following three cases were calculated for each binder using the data in Tables 4.1 and 4.2.

- Reported effective diffusivities and L's: calculated from the measured values;

- Low effective diffusivities and high L's: calculated by subtracting the 2-sigma uncertainty from the measured values, and

- High effective diffusivities and low L's: calculated by adding the 2-sigma uncertainty to the reported values.

The three cases generate a range of values such that the true value for any sample should be within this range at the $95 \%$ confidence level based upon normality assumptions for the uncertainties. See Section 4.1.

Unfortunately, the Tc-99 detection limit for the measured values was near or at the sensitivity limit for the reported concentrations. Consequently, effective diffusivity and $\mathrm{L}$ values calculated from the measured concentrations and even the 2-sigma uncertainty level may not be bounding. See Table 5-1.

Table 5-1. Range of effective diffusion coefficients and Leach Indices for all samples tested.

\begin{tabular}{|l|c|c|c|c|}
\hline Parameter & $\begin{array}{c}\text { High [Tc-99] } \\
\text { Range }\end{array}$ & $\begin{array}{c}\text { Measured [Tc-99] } \\
\text { Range }\end{array}$ & $\begin{array}{c}\text { Low [Tc-99] } \\
\text { Range }\end{array}$ & $\begin{array}{c}\text { +/-2 Sigma } \\
\text { Range all samples }\end{array}$ \\
\hline $\begin{array}{l}\text { Effective } \\
\text { Diffusivity } \\
\left(\mathrm{cm}^{2} / \mathrm{sec}\right)\end{array}$ & $1.3 \mathrm{E}-09$ to $4.9 \mathrm{E}-10$ & $1.9 \mathrm{E}-09$ to $2.1 \mathrm{E}-10$ & $1.9 \mathrm{E}-10$ to $1.1 \mathrm{E}-14$ & $1.3 \mathrm{E}-09$ to $1.1 \mathrm{E}-14$ \\
\hline Leach Index & 9.3 to 10.3 & 10.4 to 11.4 & 12.7 to 14.2 & 9.3 to 14.2 \\
\hline
\end{tabular}

In future experiments, the binders should be spiked with higher concentrations of Tc-99 and/or lower detection limits should be used to improve the accuracy of the data. If experiments are performed with actual tank heel, material, the concentration of Tc-99 in the heel must be 
compatible with leachate detection limits assuming the L's reported above. Otherwise the heel should be spiked with additional Tc-99 to achieve meaningful results.

No statistical differences were detected in the capacity of the monolithic slag-containing binders to stabilize Tc-99. Three of the binders contained slag and three contained slag and hydroxyapatite. Consequently, adding hydroxyapatite to the monolithic binders containing slag did not change the Tc-99 stabilization results. However, under some conditions, the crushed samples indicated that hydroxyapatite improved Tc-99 stabilization. (See Section 5.2.) In addition, the chemistry of the aqueous phase in contact with the binder did not effect the results for the monolithic samples.

The test results with the monolith samples demonstrate that slag is effective in reducing Tc-99 leaching from the Hanford tank heel simulants when the heel is mixed with the binder and presumably the actual fill grout. The results also demonstrate that slag is compatible (sorption of Tc-99 by slag occurred in the presence of HA) with hydroxyapatite.

Results obtained in this study are applicable to the Hanford Tank Closure Performance Assessment in that they indicate that Tc-99 is chemically stabilized in all of the reducing grout binders. However, to date CH2M HILL has not identified a minimum Tc-99 Leach Index for the stabilized tank heel/stabilizing grout.

The relatively short duration of these tests has the potential to impact the conclusions that were drawn from these data. Short-term tests do not provide time for kinetics effects (reaction rates) or for slow mass transport into or out of the materials. Consequently, the results presented for the sorption/desorption apply only to the time span over which the tests were performed.

\subsection{TC-99 LEACHING FROM CRUSHED SAMPLES}

Crushed binder leaching was intended to be an accelerated leach test and also to provide information on leaching from physically degraded tank fill grout. High external surface area is the primary expression of physical degradation.

Tc-99 leached from all six crushed binders as shown in Section 4.2. The highest leachate concentrations occurred early in the leaching, i.e., between the first and fifth day of leaching regardless of the leachate or binder composition. Resorption of Tc-99 was detected for the crushed samples exposed to DI water and the C-106 simulant between 5 and 27 days exposure. Tc-99 was not resorbed by any of the crushed binder samples in contact with the C-200 series simulant.

As discussed in Section 5.1, leaching of Tc-99 from the monoliths was not detected. Crushing of the samples increased the surface area and consequently, should have improved the sensitivity of the test to a level where Tc-99 could be detected in leachates over the time scale of the testing. However, even under these conditions, many of the Tc-99 leachate concentrations were at the level of detection because the Tc-99 resorbed or stabilized during the test period. The binder samples leached in DI water showed the most resorption as a function of leaching time. 
WSRC-TR-2004-00021, Rev. 0

January 12, 2004

Page 33 of 38

In contrast to DI water leachate, significant differences in Tc-99 concentrations were observed for the crushed samples with and without HA for the leachate that simulated the C-106 supernate chemistry. ${ }^{1}$ The presence of HA in the samples reduced the leaching by a factor of 4 . Based on these results, inclusion of HA in the grout layer would mitigate release of Tc-99 from basic rainwater.

Samples containing HA did not reduce the leaching of Tc-99 when the leachate solution was either DI water or the C-200 simulant. However, the amount of Tc-99 leached from DI water was at a low level relative to the C-106 without HA and the C-200 series. Therefore, the impact of added HA on the DI water test could not be ascertained.

These leaching tests with crushed samples demonstrate that inclusion of HA in the mix will enhance performance of the grout (less leaching) in the scenario where a basic leachate contacts the grout. It can therefore also be concluded that HA is compatible with the binder and admixture components of the grout.

\subsection{TC-99 SORPTION/DESORPTION FOR CURED CRUSHED GROUT}

\subsubsection{Water Leachate}

One scenario considered is this study was the case of rainwater entering the tank, solubilizing Tc-99 in untreated residues on the tank walls, and then contacting the cured, stabilizing grout. The question to be answered is whether the cured grout containing slag and/or HA will sorb/precipitate the Tc-99 dissolved in the infiltrating water. (The case where the infiltrating dissolves soluble salts in addition to becoming basic as a consequence of contact with the grout and/or walls of the tank will be discussed in the next section.)

The results presented in Section 4.3 clearly demonstrate that crushed cured binders sorb/stabilize Tc-99 from DI water. Furthermore, the sorption/stabilization is greatest for binders containing slag. When cured grout containing slag is exposed to DI water (rainwater) spiked with soluble Tc-99 (infiltrating rainwater), 33 to $37 \%$ of the Tc-99 is sorbed over a five-day period. The presence of hydroxyapatite in the cured grouts did not influence or participate in this Tc-99 sorption. It is worth noting that the control grout sample without hydroxyapatite and without slag sorbed $9 \%$ of the Tc-99 in solution.

Following sorption of Tc-99 on the cured binders, leaching/extraction tests were performed to determine whether the sorption was reversible or irreversible. DI water was used as the leachate. In the control samples without slag, Binders DI-7 and DI-11, all of the Tc sorbed during the first

\footnotetext{
${ }^{1}$ The C-106 simulant is essentially a basic solution $(0.43 \mathrm{M} \mathrm{NaOH})$ with a small amount of oxalate. The $\mathrm{pH}$ and ionic strength of this simulant also approximates the chemistry of infiltrating rainwater as it becomes basic after contact with the tank fill grout. Consequently, the leaching tests with $\mathrm{C}-106$ provided information on the effect of $\mathrm{pH}$ on the leaching of Tc-99 from the grout. Generally, infiltrating rainwater will achieve a $\mathrm{pH}$ in the range of about 12.5 in contact with portland cement grout while the $\mathrm{C}-106$ simulant has a $\mathrm{pH}$ of 13.6. Therefore, the $\mathrm{pH}$ values for the $\mathrm{C}-106$ simulant and DI water bound $\mathrm{pH}$ for rainwater in contact with grout.
} 
5 days of exposure was desorbed within the first 5 days of leaching in DI water. Consequently, grouts that do not contain slag readily release the sorbed Tc-99 back into DI water. The slagcontaining cured grouts retained $60 \%$ of the sorbed Tc- 99 while $40 \%$ of the sorbed Tc-99 was released to the DI water.

The presence of hydroxyapatite in the cured grouts does not participate in or influence sorption or retention of Tc-99 based on the results generated in this study. One explanation is that the surface of HA is deactivated by encapsulation/alteration during the curing process.

\subsubsection{Water Leaching of Binders with Different Processing Admixtures}

The sorption/desorption tests in DI water provided additional information on the influence of the three different processing admixtures on Tc-99 stabilization for binders containing hydroxyapatite. Binders DI-4, DI-5 and DI-6 contain identical cementitious ingredients plus HA but different processing admixtures (Kelco-Crete ${ }^{\circledR} /$ ADVA $^{\mathrm{T}}$ Flow, Methocel, and Maxflow). Binder DI-4 with Kelco-Crete ${ }^{\circledR} /$ ADVA $^{\mathrm{TM}}$ Flow released the least amount of sorbed Tc- 99 followed by Binder DI-5. Binder DI-6 released all of the Tc-99 sorbed within the first 5 days of leaching in DI water. The Maxflow admixture was added as a preformed foam and consequently added a significant amount of organic surfactant and internal porosity.

The results of these tests indicate that binders/grouts with Kelco-Crete ${ }^{\circledR} / \mathrm{ADVA}^{\mathrm{TM}}$ Flow are more effective in sorbing and retaining Tc-99 when the grout is leached in DI water (rainwater) compared to grouts made with the other two admixture systems.

\subsubsection{Effect of Tank Supernate Chemistry on Tc-99 Sorption/Desorption}

Tc-99 sorption/desorption onto and from cured grout samples using C-106 and C-200 tank supernates was intended to provide additional data for the infiltrating water scenario presented in Section 5.3.1. Since infiltrating water will not only become basic as it equilibrates with the fill grout, it will dissolve soluble salts on the walls of the tank.

Results indicate the sorption of Tc-99 is dependent on the chemistry (in this case $\mathrm{pH}$ ) of the simulated tank heel supernate. Binders C-1 and C-4 sorbed a significant percentage of Tc (80\% of the total amount of Tc-99 in the initial liquid versus $35 \%$ for DI water) from the C-106 supernate. The impact of slag is very significant since those binders without slag, Binders C-7 and C-11, sorbed less than $1 \%$ of the Tc-99 in the C-106 simulant.

Desorption of the Tc-99 was much less with C-106 than with DI water. Approximately $10 \%$ of the sorbed Tc-99 was released over the desorptive phase of testing compared to $40 \%$ release in DI water. These results suggest that a higher $\mathrm{pH}$ leaching solution will increase sorption and reduce desorption of Tc-99. These results are also important for the case where a cured stabilization layer of grout is in contact with residual C-106 supernate. In this case, the cured grout can stabilize and retain Tc-99 from the tank supernate. 
For the C-200 series supernate, binders 200-1 and 200-4 sorbed a significant percentage (86\%) of the Tc-99. In this case, binders 200-7 and 200-11 (no slag) also sorbed a significant amount of Tc-99 $(\sim 40 \%)$ from the C-200 simulant. These results are the only examples where significant amounts of Tc-99 were sorbed/stabilized in the absence of slag in the binder. Desorption of Tc-99 into C-200 leachate solution was $20 \%$, a value higher than for C-106 but lower than for DI water. Determination of the mechanism responsible for the Tc-99 sorption in the absence of slag with $\mathrm{C}-200$ simulant would require further investigation.

\subsubsection{Tank Heel Leaching of Binders with Different Processing Admixtures}

In contrast to the DI water testing, the sorption/desorption results using three different admixtures were independent of the admixture used for both C-106 (samples C-4, C-5, and C-6) and C-200 (samples 200-4, 200-5, and 200-6) supernate simulants. 


\subsection{CONCLUSIONS}

This study demonstrated that Hanford Reducing Grout (HRG 2) containing slag or slag plus surface modified hydroxyapatite not only stabilizes Tc-99 in simulated tank heels, but also retains the Tc-99 after curing. Tc-99 was introduced into the binder materials in one of two ways:

1) Mixing Tc-99 spiked water, C-106 supernate, or C-200 heel with the binder ingredients prior to curing and

2) Exposing cured Tc-99 free binder samples to three different Tc-99 spiked liquids (DI water or simulated Tank C-106 supernate or Tank C-200 average heel.

Monolith leaching per the abbreviated ANSI/ANS 16.1 test indicated that essentially all of the Tc-99 stabilized during the curing period was retained by the monolithic binder samples containing Kelco-Crete ${ }^{\circledR} / A D V A^{\mathrm{TM}}$ Flow. In this series of tests, the Tc-99 was added to the mixing water during sample grout preparation. This demonstrates that Tc-99 stabilization is not negatively impacted by using of this admixture system to achieve self-leveling and flow properties.

Stabilization of Tc-99 was demonstrated by mixing the grout components into C-106 and C-200 simulated tank supernates and into deionized water. After a 28-day curing time, the grouts were subjected to a series of leach tests.

Calculation of effective diffusivities using measured Tc-99 concentrations for each sample gave a range of values from $1.9 \mathrm{E}-09$ to $2.1 \mathrm{E}-10 \mathrm{~cm}^{2} / \mathrm{sec}$. Effective Tc-99 diffusivities, calculated with the plus/minus 2-sigma uncertainty-concentrations, gave an overall range from 1.3E-09 to 1.1E$14 \mathrm{~cm}^{2} / \mathrm{sec}$ (95\% confidence interval).

Calculations of the Leach Index (ANSI/ANS 16.1) using measured values of the Tc-99 for each sample resulted in Leach Indices ranging from 10.5 to 11.4. Leach Indices calculated using plus/minus 2 sigma uncertainties for the Tc-99 concentrations gave an overall range of values from 9.2 to 14.2 (95\% confidence interval). The values of effective diffusivities and Leach Indices can be used in support of Performance Assessment calculations performed for HLW tank closure at Hanford.

The sorption and leaching results of Tc-99 were independent of whether hydroxyapatite was present or absent in the mixes. However, additional leaching tests performed on crushed monolith samples (increased sensitivity) revealed that inclusion of hydroxyapatite in the mix reduced leaching when a Tank C-106 supernate simulant was used as the leachate solution.

Sorption/desorption tests of Tc-99, performed using cured grout samples, revealed that Tc-99 is readily sorbed from tank heel supernates and from deionized water as long as slag was present in the mixes. These tests demonstrate that infiltrating rainwater (from neutral to higher $\mathrm{pH}$ ) will sorb soluble Tc-99. Hydroxyapatite was not effective in sorbing Tc-99 once the grout had cured. This evidently results from encapsulation or alteration of the hydroxyapatite surface by the grout components. The desorption results from the testing with cured grout samples revealed that Kelco-Crete ${ }^{\circledR} / \mathrm{ADVA}^{\mathrm{TM}}$ Flow is the processing admixture of choice for the Hanford Reducing Grouts. 
WSRC-TR-2004-00021, Rev. 0

January 12, 2004

Page 37 of 38

\subsection{QUALITY ASSURANCE}

Work was conducted as a scoping study with written work instructions. Samples were prepared using calibrated balances. Data are recorded in WSRC-NB-2002-000192. 


\subsection{REFERENCES}

1. RPP -11094, Tank Closure Fill System for the Accelerated Tank Closure Demonstration Level 2 Specification, Rev. 0, CH2M HILL Hanford Group, Inc., Richland, Washington, 2002.

2. R. C. Moore, 2002. Personal communication, July 2002.

3. R. C. Moore, 2003. Personal communication, March 21, 2003.

4. R. C. Moore, 2003. Personal communication, May 20 and 21, 2003.

5. R. C. Moore, July 2003. Letter correspondence from R. C. Moore to J. Laurenz, "Experimental results from testing grout additives in formulations containing $\mathrm{Sn}+2$ treated hydroxyapatite."

6. IWO MOSRLE81, Feb 24, 2003.

7. SNL requisition.

8. J. L. Krumhansl, June 16, 2003, E-mail correspondence to J. Laurenz, et al., "Compositions for Tank C-106 Simulant and Average Tank C-200 Series Simulant.”

9. D. Reynolds, June 12, 2003. E-mail correspondence to J. Laurenz, et al., "Composition of Heels in Tank C-106, C-201, 202, 203, and 204."

10. ANSI/ANS 16.1, 1986. "Measurement of the Leachability of Solidified Low-Level Radioactive Wastes by a short-term Test Procedure," prepared by the American Nuclear Society Standards Committee Working Grout ANS-16.1, Approved April 14, 1986 by the American National Standards Institute, Inc. American Nuclear Society, 555 N. Kensington Ave., La Grange Park, IL 60525.

11. ASTM D-5233 1992 (R 1999). "Standard Test Method for Single Batch Extraction Method for Waste Distribution," American Society for Testing and Materials, Philadelphia, PA 19103.

12. ASTM D-4646 1987 (R 2001). "Standard Test Method for 24-Hour Sorption Test and Distribution Ratios by the Short-Term Batch Method," American Society for Testing and Materials, Philadelphia, PA 19103.

13. ASTM D-4319, 1993 (R 2001). "Standard Test Method for Distribution Ratios by the ShortTerm Batch Method," American Society for Testing and Materials, Philadelphia, PA 19103. 